\title{
INFLUENCES ON THE SUICIDE CRISIS AMONGST FIRST NATION YOUTH IN NORTHERN ONTARIO
}

by

Amanda Sellers, BSW, Ryerson University, 2019

\author{
An MRP \\ presented to Ryerson University \\ in partial fulfillment of the \\ requirements for the degree of \\ Master of Social Work \\ in the Program of \\ Social Work
}

Toronto, Ontario, Canada, 2020

(C) Amanda Sellers 2020 


\section{AUTHOR'S DECLARATION FOR ELECTRONIC SUBMISSION OF A MRP}

I hereby declare that I am the sole author of this MRP. This is a true copy of the MRP, including any required final revisions.

I authorize Ryerson University to lend this MRP to other institutions or individuals for the purpose of scholarly research

I further authorize Ryerson University to reproduce this MRP by photocopying or by other means, in total or in part, at the request of other institutions or individuals for the purpose of scholarly research.

I understand that my MRP may be made electronically available to the public. 


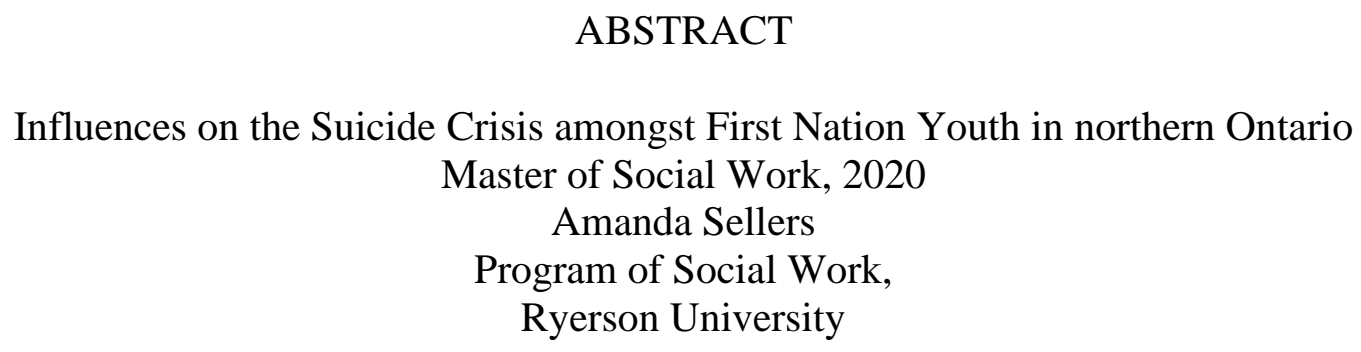

Suicide is an ongoing crisis for many First Nation communities in northern Ontario. First Nation youth taking their own lives has become highly prevalent in many small communities, leaving behind friends and family struggling with grief and loss. Despite a significant volume of literature on the suicide crisis, there are some gaps that continue to be seen on the influences on First Nation youth suicide. In utilizing secondary data analysis (SDA), this research explores the those influences in these areas: First Nation people's access to resources, grief and loss to suicide, the effects of Indian Residential School, and one's connectedness to land, spirituality and culture. I discuss the effects of colonization and intergenerational trauma in relation to the findings. This research is conducted in hopes to expand future suicide prevention strategies and encourage ways the social work profession can better provide services for First Nation communities. 


\section{TABLE OF CONTENTS}

Chapter 1: Introduction

Chapter 2: Literature Review

Chapter 3: Theoretical Framework

Chapter 4: Methodology

Chapter 5: Findings

Chapter 6: Discussion

Chapter 7: Conclusion
Page \#1

Page \#8

Page \#35

Page \#40

Page \#47

Page \#69

Page \#86

Page \#91

References 


\section{CHAPTER 1. INTRODUCTION}

In Canada today, the lives of First Nations ${ }^{1}$ people continue to look drastically different than the lives of those within the non-Indigenous population. As the national claims for cultural diversity grow across the country, Indigenous people as a whole remain a highly marginalized group in Canadian society. Elias et al. (2012) discuss that the effects of colonization in Ontario, such as the Indian Residential School (IRS) system, have left many First Nations people with experiences of trauma and high rates of suicidal behaviour. Therefore, through the use of this research paper, I seek to address and explore the influences on the current suicide crisis amongst First Nation youth in northern Ontario communities. I am specifically focusing on northern Ontario communities because of my experience working in such areas with First Nation youth. Though I understand that the crisis of suicide is occurring in many Indigenous communities across the province, I recognize the different experience for those living in northern Ontario, where isolation and limited access to services, such as mental health, are greater concerns than in southern communities (Nault, 2017). Furthermore, Mew et al. (2017) discuss how "within the remote reserves north of Sioux Lookout and NAN² Territory" (p.1), there are also severe healthcare inequalities in comparison to other communities. In understanding the difference mentioned by Nault (2017) and Mew et al. (2017), I believe focusing on northern Ontario is important to my MRP because of how the experience and influences regarding suicide may look different with youth who live in isolated northern communities compared to those who do not.

\footnotetext{
1 "First Nations refers to [the] group of people officially known as Indians under the Indian Act, and does not include Inuit or Métis peoples" (Vowel, 2016, p. 11). I acknowledge that suicide is also an issue for Inuit and Métis people, and even more prevalent in Inuit communities than First Nation communities (Eggertson, 2013). I focus only on First Nations people in my research due to my personal experience working with First Nation communities as well as for the purpose of being concise within the constraints of this MRP.

${ }^{2}$ NAN refers to Nishnawbe Aski Nation (Mew et al., 2017). NAN is described by Mew et al. (2017) as a First Nations political organization representing the 49 First Nation communities located in northern Ontario, where many happen to be situated in the remote and far north regions of the province,
} 
Suicide is one of fastest rising public-health issues currently facing Canadians today (Cutcliffe, 2005). In considering the experiences of mental health struggles amongst the First Nation population, Cutcliffe states that suicide currently remains to be the leading cause of death for First Nation youth in northern Ontario (2005). Reflecting on suicide prevention initiatives over the years, greater efforts are necessary in supporting the mental health needs of this specific population. Drawing on the concept of mental health, it is important to discuss how trauma is inherently implicated in the lives of First Nations people. Baskin (2016) explains the term, collective trauma. Baskin states that collective trauma not only acknowledges the racism faced throughout history and its impacts on Indigenous peoples today, but also how that racism continues to traumatize (2016). Waldram (2004) discusses collective trauma in relation to mental health and suicide amongst First Nation youth, stating "trauma is removed from the level of the individual and becomes embedded in community, in culture, and in history. It becomes something that is shared, taught, and embraced as well as experienced" (p. 221). Understanding this concept, the idea of trauma is not only experienced at a single point in time and only by one person but is carried forward as a community issue. Moreover, Waldram (2004) highlights how the continuity with the past trauma "is expressed primarily in terms of the intergenerational nature of the trauma, the manner in which it can be passed down through the generations to be successively re-experienced” (p. 221). Therefore, understanding the ideas made in Baskin (2016) and Waldram (2004), trauma can be understood as an ongoing experience across generations and more so, how this trauma now affects First Nation youth experiencing mental health struggles. Recognizing how the suicide crisis is implicated, Kirmayer et al. (2000) draws connection with the idea of collective trauma and suicidality, explaining that suicide has become "one of the most dramatic indicators of distress in Aboriginal populations. Many First Nations, Inuit, and Métis 
communities have elevated rates of suicide, particularly among youth" (p. 610). Moreover, in Menzies (2010), the author explains specifically how the issue with collectively experienced trauma is a contributor to how mental health and suicidality are disproportionately represented for Aboriginal peoples. For example, Menzies (2010) states that collective trauma and suicidality are connected due to the historical injustices and oppression for Aboriginal peoples that continues to impact them, mainly through acts of racism and discrimination. Thus, realizing how historical trauma has become an intergenerational and community experience, First Nation youth suicide is not simply an individual crisis, but a systematic crisis that has stemmed from decades of historical oppression and needing to be further addressed.

Through researching this topic, I feel it is important to shine light on an issue that I draw a personal connection and meaning to, based on my experience working with First Nation youth as a mental health and crisis counsellor in remote, northern Ontario communities. This topic is valuable research to me due to my frontline social work experience seeing how First Nation families are impacted by mental health and suicide on a daily basis. As a counsellor who has lost youth to suicide, I believe that the health and mental health of Indigenous people across Canada needs to be better addressed moving forward in the current society. As a researcher who socially locates as mixed-race, I recognize the privilege I carry in many spaces but also the spaces I do not. Being a mixed-raced individual, I believe there are many complexities to my identity and often find it hard to explain. For example, I am made up of British, Scottish, and German blood. But I am also Thai ${ }^{3}$, Chinese and Vietnamese. Recognizing the major cultural differences between a Thai person and Chinese person or a British person and a German person, I often find

\footnotetext{
${ }^{3}$ Thai, meaning a person from Thailand.
} 
it difficult to determine how I should identify. Therefore, I personally choose to be identified with mixed-race, as I feel this term explains who I am in a concise and more truthful way.

Understanding my experience living in the current society as a non-Indigenous person, it is my responsibility to be aware of how my social positioning is implicated in my professional work as well as in my research on Indigenous issues. In working with First Nation communities, I have made it important to acknowledge and understand to the best of my ability how historical trauma and the impacts of colonization affect those I work with today. As a researcher, I also recognize these problems but I also want to understand that as a non-Indigenous researcher of Indigenous people and issues, it is important to consider how to take on a decolonizing approach. Drawing from Puch-Bouwman (2014), the author suggests adopting a rectificatory position, which means to apply the principle of "trans-generational justice towards healing of colonial damages" (p. 410). Puch-Bouwman (2014) does addresses the concern where Indigenous research has often been led by those who were non-Indigenous. Discussing this issue, the author proposes that researchers not only take a decolonizing approach but to address the "colonial issues in their [own] research work, which in turn affect their practices" outside of research (Puch-Bouwman, 2014, p. 409). These concepts are incorporated into my work as I critique the colonial ways of thought within my methodology chapter and discussion chapter, as well as recognizing my responsibilities as a non-Indigenous researcher to re-examine my own methodological and epistemological assumptions (Puch-Bouwman, 2014). Furthermore, I believe it is important in this discussion to recognize my own privilege being in a research position as well as being a non-Indigenous person. Drawing from Olsen (2018), the author states for example that "those having a privileged position doing research on issues related to people in less privileged positions are in danger of reproducing privilege and lack of privilege despite their 
good intentions" (p. 210). Reflecting on this idea, the concern raised is an important factor to recognize and thus, I need to make sure I constantly reflect on my own privilege as well as being mindful not to reproduce it throughout my MRP. Moreover, I not only agree with but hold on to the words of Olsen (2018) when they state, "as a non-Indigenous scholar of Indigenous studies, I follow in colonial footsteps. Despite the intentions I might have, my scholarly positions are symptoms of the colonial aftermath... As a non-Indigenous scholar, I can only go so far as my limitations of being non-Indigenous carry me" (p. 212). In reflecting on my research position as a non-Indigenous person, I understand that I am rooted in colonialism. No matter how I attempt to make my research intentions good, it will always be limited as Olsen (201) says. Therefore, through my research process and findings, I want to continually recognize both the privilege I carry and the colonial underlying of being non-Indigenous. Lastly, I want to consider the ways in which I can discuss the findings in a perspective that encourages justice for Indigenous people and healing from the effects of colonialism.

My professional experience working with First Nation communities has been a precious and rich cultural opportunity that has personally changed how I view the world. In understanding that the suicide crisis amongst First Nation youth is a multilayered issue and is affected differently across the intersectional identities within that population, I also acknowledge how the profession of social work can do better to support this community. When reflecting on the systematic and colonial oppression faced by First Nations people every day, it is important for myself as a future social worker and for the social work profession to acknowledge its complicity and reproduction of colonialism, and develop ways of practice that centre and respond to First Nations people in appropriate ways. Social work has oppressed Indigenous peoples and continues to do so through its colonial systems, such as child welfare, and needs to change. 
Social work can better service Indigenous communities through adopting a culturally-informed practice that understands the influences to suicide within the unique context of First Nations people. Furthermore, it can encourage the change in the societal perceptions of First Nation mental health and the direction of care for the future.

By understanding culturally-informed practice, Brady et al. (2016) explains that being culturally-informed is to acknowledge and respect the cultural and social factors of individuals during professional or therapeutic encounters as well as respecting the beliefs and values underlying their experience. Being culturally-informed does not necessarily mean cultural safety nor cultural competency, as they are similar but differ for a few reasons. For example, Mkandawire-Valhmu (2018) describes cultural safety as "actively examining social, economic, political positions and power differences" (p. 2) and how an environment that does not respect diverse cultures can cause institutional racism, re-create trauma and dehumanize vulnerable populations. Whereas, cultural competency means the process in which social workers are respectively responding to people of all cultures and other factors of diversity that value and recognize the worth of people and communities as well as preserving their dignity (Greeno et al., 2017). Therefore, by social workers adopting a culturally-informed practice, it differs in which it is not discussing an environment of safety like cultural safety or preserving a person's dignity like cultural competency, but to acknowledge and respect the cultural factors of individuals (Brady et al., 2016). I have chosen to highlight culturally-informed social work practice because in working with Indigenous peoples, cultural safety does not seem appropriate since I believe as long as colonized spaces exist, Indigenous safety will continue to be at risk. Moreover, I do not use cultural competency because I believe attempting to preserve another person's dignity suggests a White-saviour mentality and, by drawing from Brady et al. (2016), response to culture 
"is not a static competence to be achieved once, but a continually evolving process" (p. 121). By considering how the social work profession is implicated in this context, my hope for this major research paper is to facilitate discussion on the influences of First Nation youth suicide, in order to inform how social workers and the current society can better support First Nation communities in the years to come.

In the following chapters of this research paper, I intend to explore the topic of the Influences on the Suicide Crisis amongst First Nation Youth in northern Ontario. I provide in Chapter 2 a review on the relevant literature found to date on this research topic. In Chapter 3, I discuss the important theoretical frameworks that inform this research study and will carry through in how I collect and analyze data. In Chapter 4, the specific research methodology that situates my research will be addressed - including data sources, methods, population sample, and the data analysis approach. In Chapter 5, the findings found throughout the data sources will be discussed in relation to my research topic. Furthermore, Chapter 6 is a discussion on those findings and bringing in interpretations on data. Lastly, Chapter 7 addresses several concluding points and implications for future social work practice. 


\section{CHAPTER 2. LITERATURE REVIEW}

In the literature, I have consulted several studies along with peer reviewed articles that relate to my research topic. While searching for relevant articles, the search terms and combinations I used were "First Nation", "youth", "suicide", "Ontario" and "crisis". I had chosen to mix up the combinations a couple times, such as searching "First Nation youth suicide Ontario", "Ontario First Nations suicide", "First Nation youth suicide crisis Ontario", and "Ontario suicide crisis First Nation youth". The databases I used to search for information was Social Services Abstract, JSTOR, Social Work Abstracts and ProQuest.

The literature that I have found to date consist of a variety of articles that relate to my research topic. Amongst the findings, a newspaper article by Talaga (2017) discusses the suicide crisis in Wapekeka, Ontario - as the community had suffered from their fourth loss of a young girl to suicide in 2017. Talaga mentions the lack of access to mental health resources as well as highlighting the trauma for survivors due to Ralph Rowe sexual assaults. Ralph Rowe was a Catholic priest convicted in 1994 for over 39 counts of sexual assaults towards First Nation boys in Ontario, which left many victims still affected by the trauma today (Talaga, 2017). This article is helpful for my research topic, as it discusses the relation between sexual assault and suicide involved specifically in that community's losses.

In another newspaper article, Gignac and Winter (2017) bring in a different perspective to the issue of suicides happening at high rates. Specifically, the authors make note of the underlying causes of these suicides in relation to the foster care and child welfare system. Furthermore, Gignac and Winter (2017) highlight the underfunding for education and on-reserve infrastructure being an involved factor as well. In continuing this discussion, Palmater (2011) outlines the reality of many First Nation communities in northern Ontario. The author writes that 
basic necessities to life are often not present, such as water and food security, employment, and poor education (Palmater, 2011). Additionally, Palmater (2011) explains how this disparity, through colonialism and racism, contributes to having youth that experience social exclusion when forced to live away from home due to lack of housing. The article discusses in more depth the impact of poverty on young people taking their own lives, which I understand as valuable knowledge to support my research. Focusing on the political side of this issue, Button (2016) is another article that is useful for my topic. Button talks about how conversations on suicide need to consider it being a problem of equal justice and human dignity, including how enduring specific social conditions contribute to the breach of that same justice and dignity - ultimately, affecting suicide risk (Button, 2016). In contrast to the other articles thus far, this article adds connection to how social justice is implicated.

Lastly, I bring attention to a newspaper article by Jones (2011), who discusses how there is a relation between educational resources and suicide. The author writes how the crisis of suicide has been so severe, that one of the northern First Nations communities have experienced as much as 16 youth suicides between 2006 to 2008 (Jones, 2011). In drawing connection of how education is involved with these suicides, Jones (2011) explains that many youths do not attend school regularly because there are insufficient programs that encourage positive relationships and motivate them in wanting to attend school. While reading this article, I was able to make several personal connections to my own frontline experience. For example, I have worked with many youths who have stopped attending school before the age of 14 as well as youth who attend only a couple days out of the year. Furthermore, those who do not attend have identified no motivation to do so and believe their needs are not accurately met to stay engaged. 
In search for relevant literature, the concept of cluster suicide was brought up in one of the articles. For example, in articles by Eggertson (2015) and Tempier (2016) the authors discuss that often suicide amongst Aboriginal youth happen in clusters - many suicides happening in a small period of time or close together. In Eggertson (2015), the author states how a recent study had found suicide clusters occurring of three to five youth in northern Ontario First Nation communities. Furthermore, the author states that these clusters mean that the deaths are happening within months of each other and drive one another, such as in remote communities of Pikangikum First Nation and Red Lake First Nation, adding to the increasing suicide rates in Ontario (Eggertson, 2015). Cluster suicide was also discussed in an article by Dunn (2013), who addresses how there were up to 10 suicides in Pikangikum First Nation in 2007 alone - a oneyear period. Furthermore, Dunn (2013) states that cluster suicides or copy-cat suicides can be understood to belong "to a group of youth where a member has committed suicide leaves the remainder of the group at a high risk for suicide" (p. 27). To be specific, the author explains that vulnerable members of the group who had experienced belongingness and, in an effort, to regain that belongingness, are at risk to attempt suicide if not well taken care of through social support (Dunn, 2013).

\section{Collective Trauma}

In the search for relevant literature, several articles found had discussed the idea of collective trauma in relation to suicide amongst First Nation youth today. As I mentioned in the introduction chapter, Kirmayer et al. (2000) discuss how this idea relates to mental health, and particularly suicidality in Indigenous communities. The authors discuss how in discussing suicide and indicators of distress across Indigenous communities, it is important to consider "the different ways in which groups have responded to the ongoing stresses of colonization, 
sedentarization, bureaucratic surveillance, and technocratic control.” (Kirmayer et al., 2000, p. 611), stating that it is likely these factors have contributed to the "high levels of emotional distress and problems like depression, anxiety, substance abuse, and suicide" (p. 611). Therefore, it is not that suicide is caused by Indigenous people themselves, but instead Kirmayer et al. (2000) suggests that suicide has been due to the collective trauma experienced from the ongoing colonialization and control of Indigenous communities, acknowledging how the grief, loss, and collective trauma due to colonialization and colonial policies are directly reflected in the mental health issues amongst Indigenous peoples. Furthermore, In Kirmayer, Simpson and Cargo (2003), the authors also discuss collective trauma. Specifically, the authors state that "for Canadian Aboriginal peoples, the revelations of the evils of the residential schools have made notion of individual and collective trauma salient. Some Aboriginal people have made use of communal setting to tell the story of their suffering. In these accounts, individual traumas and losses may be explicitly linked to collective traumas" (Kirmayer et al., 2003, p. S20). In this discussion, the authors address how collective trauma helps to understand the origins of problems Aboriginal youth are facing in relation to suicidality, as this concept attempts to understand mental health struggles as not an individual problem but a political issue throughout history (Kirmayer et al., 2003). Therefore, by recognizing the root of trauma as a collective experience due to colonization, it helps to outline the oppressive reality Aboriginal youth live in today that drive thoughts of suicide.

Menzies (2010) also brings up how collective trauma is related to suicidality amongst First Nation youth but adding in the idea of intergenerational trauma. For example, Menzies (2010) states that "the issue of trauma, specifically intergenerational trauma is explored in great detail as a contributor to the explanation of the disproportionate representation of mental health 
issues among Aboriginal people" (p. 65). The collective trauma experienced by parents and their children as a result of IRS policy "continues to have consequences for subsequent generations of children" (Menzies, 2010, p. 67) - meaning, intergenerational trauma. Similarly, Waldram (2004) had expressed this idea of the intergenerational nature of trauma, as mentioned in the previous chapter. Understanding the idea of cumulative impacts of trauma and how it affects people intergenerationally, the literature addresses how this has been a major cause for mental health in relation to First Nation youth suicide.

In discussing collective and intergenerational trauma, Menzies (2010) states how it is good to consider the implications of mental health in relation to the collective trauma, but that it is also important to understand why higher rates of mental health issues are experienced amongst Indigenous peoples than non-Indigenous people. Specifically, Menzies states

If we do not consider mental illness within the context of historical injustices then we are collecting and presenting information in a vacuum, and perpetuating the stereotype that Aboriginal peoples are more susceptible to mental illnesses then the general Canadian population (p. 66-67).

Thus, it is critical that the idea of collective and intergenerational trauma influencing mental health and suicidality is also conceptualized within colonization being the root cause.

\section{Cultural Continuity}

Reflecting on the relevant literature, the concept of cultural continuity was also raised in relation to suicidality amongst First Nation youth (Bodnar, 2014; Chandler \& Lalonde, 1998, 2008; Hallett et al., 2007; Kirmayer et al., 2000; Kirmayer et al., 2003; MacNeil, 2008;

McCormick et al., 2013). In Bodnar (2014), Chandler \& Lalonde (2008), Hallett et al (2013) and Kirmayer et al. (2000), the authors suggest that the experience of cultural disconnect has shown 
to be an influence on increased rates of youth suicide as well as other mental health issues in Aboriginal communities. For example, Bodnar (2014) brings in the idea that the high rates of suicide amongst this population are largely due to issues of intergenerational trauma linked to colonial policies. Moreover, Bodnar noes that through intergenerational trauma, cultural continuity had been lost and shown to affect the suicide rates amongst Aboriginal youth (2014). Similarly, Chandler and Lalonde (2008) explain how suicide amongst First Nation youth is 5 to 20 times higher than those that are non-Indigenous and that this risk is magnified within this population because of the lack in one's sense of selfhood through their ways of life and culture. To explain, the authors suggest that cultural continuity involves how,

One's culture can be counted on to provide young people a measure of sameness...if instead, one's culture is marginalized, or vandalized, or turned into a laughingstock; and if (because of colonization or decolonization or globalization) the familiar and trustworthy ways of one's community are criminalized, legislated out of existence, or otherwise assimilated beyond easy recognition, then woe be upon those transitioning toward maturity, and for whom otherwise customary ways and means of warranting one's personal persistence often no longer suffice (Chandler \& Lalonde, 2008, p. 4).

In the articles, the authors also suggest how cultural continuity linked to suicidality is not only a matter of the present but that the history of colonization has led to the current suicide crisis and mental health problems for Aboriginal people (Bodnar, 2014; Chandler \& Lalonde, 2009; Hallett et al., 2007; Kirmayer et al., 2000; Kirmayer et al., 2003; MacNeil, 2008; McCormick et al., 2013). For example, Kirmayer et al. (2000) state that cultural discontinuity "can be readily understood as the direct consequences of a history of dislocations and the disruption of traditional subsistence patterns and connection to the land" through colonialization 
(p. 609). In addition, McCormick et al. (2013), address how the effects of colonial oppression is seen as a factor in the development of cultural identity, in regard to suicidality. Furthermore, McCormick et al. (2013) state that even with the awareness of suicide, there is the need to consider the impacts of colonization affecting one's relationship to culture. In MacNeil (2008), the author also addresses the impact of colonization on cultural continuity. For example, MacNeil (2008) state that cultural continuity and historical conditions were found to be causal factors for high rates of suicide amongst Aboriginal people, noting specifically, that "colonial policies related to residential schools, reserve communities, loss of traditional lands, and erosion of language and cultural traditions that lead to cultural continuity have created a loss of cohesion and identity in Aboriginal communities which have impacted family health behaviors" (p. 6). Lastly, Kirmayer et al. (2003) adds to the discussion, as they explain how cultural continuity in relation to suicide can be expressed in different ways, but that they all depend on the impact of colonization where culture has been enduring and linked through historical transformation.

Within cultural continuity in relation to suicidality, the idea of traditional healing was discussed throughout the article as connected to suicide prevention. In Kirmayer et al. (2000), the authors discuss how the idea of culture and mental health can be understood through traditional service promotion for Aboriginal people to address the issue of suicide. For example, the authors state how there are

Many forms of traditional healing that are currently undergoing a renaissance and spreading across diverse cultures and communities must be considered from this larger perspective. The resurgence of interest in traditional practices like the sweat lodge (and their adoption by Aboriginal communities that never had such traditions) is part of a more 
global movement to regenerate Aboriginal identity and explore the significance of an evolving tradition in the contemporary world (Kirmayer et al., 2000, p. 614).

While reflecting on the need for traditional methods to help address cultural discontinuity, Kirmayer et al. (2000) recognize that government and professionals may be supporting methods of traditional healing, but not actually addressing the root causes of suffering, such as the need to address issues around restoring Aboriginal rights, redistribution of power, and land claims. Lastly, the authors state that services must allow "community development and local control of health care systems ... [to be] responsive to local needs but also promote the sense of individual and collective efficacy and pride that contribute to positive mental health" (Kirmayer et al., 2000, p. 614). Drawing from McCormick et al. (2013), the authors discuss that there needs to be more consideration and research on the traditional methods of recovery and healing for Indigenous youth experiencing suicidal ideation as well. In relation to cultural continuity and suicide, McCormick et al. (2013) explains that "very little research has focused on solutions to the problem of suicide among Indigenous people... while noting that much research exists on the causes of suicide... [there is] the need for evidence-based recovery interventions" (p. 352). The authors continue and recommend that to address this issue, there needs to be the "teaching [of] positive self-image, exploration of traditional healing practices, and the re-introduction of traditional cultural activities" (McCormick et al., 2013, p. 352). Therefore, the authors are discussing how one of the ways suicide prevention needs to be addressed is to consider the reintegration of culture and bringing back cultural continuity. Similarly, Kirmayer et al. (2003) also discuss cultural continuity and suicide in the context of traditional healing for mental health. For example, Kirmayer et al. (2003) state the importance of "a focus on the Creator, the symbolism of the medicine wheel, the use of the sweat lodge and traditional plant medicines, 
pow-wow costume dances, drumming and tobacco offerings" (p. S20). Particularly, the authors suggest that cultural discontinuity has affected these ways of traditional healing as well as traditional roles. Kirmayer et al. (2003) state that because of the loss in culture, traditional healing and roles were displaced. Furthermore, this displacement caused people to experience the loss of status and direction, where discontinuity in one's role was has contributed to high suicide rates amongst Aboriginal youth (Kirmayer et al., 2003).

In the articles, the concept of suicide prevention and protective factors were discussed in relation to cultural continuity. For example, Chandler and Lalonde (2008) offer a strong argument to how cultural continuity is implicated in suicide prevention, as they argue that having cultural continuity is a protective factor against suicide. More specifically, the authors found that First Nation communities who are able to preserve the cultural heritage are more successful in protecting the suicide risks amongst their youth (Chandler \& Lalonde, 2008). Thus, it is significant to note how culture is an important factor to consider when attempting to understand First Nation suicide, as it is not only an influence for suicidality but a protective factor at the same time. In another article by the same authors, cultural continuity is also addressed in relation to suicidality. In Chandler and Lalonde (1998), the authors reiterate the same idea of "selfcontinuity and its role as a protective factor against suicide" (p. 192). Furthermore, they express that communities with diminished cultural continuity, the youth are in an increased period of risk during adolescence and thus, the need "to develop more adequate self-continuity-warranting practices" (Chandler \& Lalonde, 1998, p. 192) is crucial. Drawing from Kirmayer et al. (2003), the authors discuss suicide prevention in relation to cultural continuity as well. For example, the authors suggest that in order to address mental health and suicidality of Aboriginal youth, it is important to make family and community the primary focus (Kirmayer et al., 2003). In 
particular, the authors state that focusing on collective cultural identities can help one's individual identity and self-esteem to improve and therefore act as a preventative resource for suicidality (Kirmayer et al., 2003). Additionally, this concept was also seen in Bodnar et al. (2014). In understanding the impact of cultural continuity on suicide, Bodnar (2014) discusses the need for revitalizing cultural traditions as a suicide prevention method. Specifically, Bodnar (2014) addresses how traditional practices, such as drumming and sweat lodges were ways to help communities and individuals heal from their losses to suicide and their own suicidality. In the article, Bodnar (2014) stresses how cultural continuity is strongly linked to one's decision to die or to live, nothing that in communities that had higher cultural continuity, the suicide rates were lower. Thus, Bodnar (2014) suggests that cultural continuity is essential to addressing the suicide crisis because it helps youth to have connection with a personal identity and that overtime, it creates stability in their sense of selfhood and overall functioning. Therefore, by reflecting on Bodnar (2014)'s views on cultural continuity, suicide and suicide prevention must be addressed through developing cultural continuity and identity. Bodnar (2014) states that suicide is a direct response to cultural identity losses and that many youth who choose to die by suicide are confused about what their beliefs are. With this understanding, the author states that cultural teachings are seen to be effective sources of intervention and prevention to address suicide amongst Aboriginal youth (Bodnar, 2014). Lastly, in MacNeil (2008), the author acknowledges that past methods to address suicide have be inadequate. MacNeil (2008) suggests that considering strategies for suicide prevention within cultural continuity is crucial for success. Due to this loss in culture stemming from colonization and discrimination throughout history, MacNeil (2008) notes that there are now many "First Nations youth who need to be empowered within the context of their own culture" (p. 6). The author states that many Aboriginal youth 
actually feel a sense of shame about their fractured cultural environment and because of the racial stereotypes in society, their self-worth is diminished, and feelings of suicide can arise (MacNeil, 2008). Therefore, MacNeil (2008) suggests the importance of cultural continuity "as a safety net and a comfort in times of despair" (p. 9) for Aboriginal youth and to address the issue of suicide.

Within the idea of cultural continuity and suicide, Hallett et al., 2007) bring in a different issue that is needing to be address. Highlighted throughout the article, the concept of Indigenous language is one of the cultural factors discussed in detail. For example, the authors state that "while the notion of 'culture' is ordinarily taken to be more inclusive, language is widely regarded as 'one of the most tangible symbols of culture and group identity - a link that connected people with their past, and grounds their social, emotional and spiritual vitality"” (Hallett et al., 2007, p. 393). Thus, the article focuses on the idea that the loss of language has created confusion for how Indigenous people look at the world and make sense of life (Hallett et al., 2007). In relation to suicide amongst Aboriginal youth, the authors state that due to the discrimination of within cultural discontinuity, suicide is shown to be higher for youth in communities without conversational use of Aboriginal language (Hallett et al., 2007).

Under the umbrella of cultural continuity and suicide, the idea of relational connectedness was highlighted as a cultural factor within a two of the articles (Kirmayer et al., 2000; McCormick et al. 2013). For example, in Kirmayer et al. (2000), the authors discuss how cultural continuity in relation to suicide is not only simply identified by the certain traditions or unique culture of an Indigenous person, but that culture should be "defined relationally, and the well-being of the family, band or community is given central importance" (p. 612). Even though individual support is crucial as well, the notion of one's relationship to others and aspects of their 
culture should be highlighted (Kirmayer et al., 2000). Kirmayer et al. (2000) states that "many Aboriginal peoples have what might be better termed an 'ecocentric' concept of the person in which other people, the land, and the animals are all in transaction with the self and indeed, in some sense, constitute aspects of a relational self $(89,90)$. Damage to the land, appropriation of land, and spatial restrictions all, then, constitute direct assaults on the person (81)" (p. 612). Therefore, drawing from Kirmayer et al. (2000), understanding how culture is relational through one's relationship with others, land, and animals is important when considering how the disruption of cultural continuity has affected the current First Nation youth suicide crisis. McCormick et al. (2013) also address the idea of relational connectedness as involved in conversation of Indigenous suicide. For example, the authors note that a youth's relationship to their parents, peers and others helped to create a sense of connection for them, which is an important factor for suicide prevention (McCormick et al., 2013). In addition, McCormick et al. (2013) suggest that along with relationships with people, one's relationship with spirituality, nature and traditions were beneficial in rebuilding cultural identity or continuity. Thus, in understanding suicide amongst First Nation youth it is crucial to recognize how relational connectedness is involved, because it outlines the ways in which relationships influence both suicidality of an individual as well as suicide prevention.

Reflecting on the relevant literature on First Nation suicide, this issue can be understood to have strong relationships with collective trauma and cultural continuity. In Kirmayer et al. (2000), Kirmayer et al. (2003) and Menzies (2010) the authors discuss collective trauma where suicide is not simply an individual experience but experienced collectively due to the traumas of historical colonization. In Bodnar (2014), Chandler and Lalonde (1998, 2008), Hallett et al. (2007), Kirmayer et al. (2000), Kirmayer et al. (2003), MacNeil (2008), and McCormick et al. 
(2013), the authors bring in the concept of cultural continuity and how cultural disconnect, such as through language and traditions, have influenced suicide amongst First Nation youth.

Therefore, with this relevant literature in mind, I hope to draw connections to these concepts in the findings of this research.

In continuing the discussion on relevant literature, there exists data within particular research studies in addition to the previous articles that relate to my research topic. Throughout the relevant studies, there are other important themes that have stood out and will be addressed.

\section{Indian Residential School (IRS)}

In considering the findings of the studies by McQuaid et al. (2017) and Bombay et al. (2019), both studies discuss a strong correlation between an individual whose parent had attended IRS ${ }^{4}$ and the experience of suicidal ideation/attempts throughout that individual's life. Comparing both studies, Bombay et al. (2019) highlight the implications this has on the parents' own suicidal ideation/attempts due to attending IRS as well as how it affects the youth of those parents, whereas McQuaid et al. (2017) only discuss the impact on the generations following the parent who attended IRS. This is an important theme that I hope to use in supporting my research paper when discussing the impacts of IRS on youth suicide today. I would also like to draw attention to the fact that in both studies, the researchers only sampled from the population that specifically lived on-reserve.

\section{Childhood Trauma and Sexual Abuse}

A second theme that emerged out of the research was in relation to childhood trauma (and sexual abuse) being correlated to mental health and suicide ideation/attempts when

\footnotetext{
${ }^{4}$ I have chosen to use the term Indian Residential School in this MRP, as much of the literature found has described this experience using this language. I do recognize the concept of Residential School Syndrome though, as highlighted in Waldram (2004). Waldram (2004) utilizes the term Residential School Syndrome to describe the experience of trauma constructed by residential schools, instead of saying IRS.
} 
becoming youth. The studies done by Elias et al. (2012) and Hamdullahpur et al. (2018) bring in the idea of how childhood experiences of sexual abuse and trauma are factors in an increased risk of suicidality. Specifically, in Elias et al. (2012), the researchers explore how abuse as a child affects the mental well-being of that individual when they become an adult, reflecting on both the impacts of attending IRS as well as living on-reserve in the context of Indigenous families. In understanding abuse and suicide, I want to make note that abuse is not only present in Indigenous communities, as that idea can often perpetuate negative stereotype about Indigenous families. Rather, Elias et al. (2012) is only speaking within the context of Indigenous people. Drawing from Canadian Incidence Study of Reported Child Abuse and Neglect (Trocmé et al., 2010), abuse reports were actually seen to be higher amongst those who were non-Indigenous than those who were Indigenous. Reflecting back to Elias et al., the authors found that up to $48 \%$ of Residential School attendees and 37\% of non-attendees living on-reserve reported past experiences of abuse. Furthermore, 28-30\% of both of those samples reported histories of suicide attempts in response to that abuse (Elias et al., 2012). I have considered that this particular study may also fall into the previous theme, but I believed it was better suited in this discussion due to the added elements of abuse outside of what was experienced in attending IRS and how that abuse is an influence to youth suicide.

Looking at the study by Hamdullahpur et al. (2018), the researchers make a direct link to Childhood Sexual Abuse (CSA) as a "multifaceted problem", that is strongly associated with suicide attempts throughout teenage years and adulthood. Additionally, the results showed that there is also a correlation between negative home environments and substance misuse with history of CSA. To clarify, Hamdullahpur et al. (2018) is only discussing abuse within the context of Indigenous families. In both Elias et al. (2012) and Hamdullahpur et al. (2018), the 
outcomes are relatively similar with the concepts of childhood abuse and trauma affecting suicidal behaviours within Indigenous communities, but as mentioned previously regarding Elias et al. (2012), reports show that abuse is not significantly higher in Indigenous families than in non-Indigenous families (Trocmé et al., 2010).. In my MRP, I use these concepts and discuss how they are implicated in the suicide crisis amongst First Nation youth.

\section{Discrimination of Women}

In breaking down the articles thematically, women are a common factor discussed in the studies related to the risk of suicide ideation and attempts. For example, in the studies by Maranzan et al. (2011) and Dunn (2013), they both recognize the increased rates of suicidal behaviour in women than in men. In Dunn's study, the researcher states that even though "fewer women completed a suicide attempt than men, they are three times more likely to attempt suicide" (2013, p. 26). This is critical information I would like to notice if it appears throughout the findings when writing my research paper, as I am interested to consider how the experiences of First Nation women differ from First Nation men. Drawing attention to Maranzan et al. (2011), the researchers address this theme in their study as they infer that because First Nations women continue to experience inequalities in both social and economic status, there are large health and well-being disparities compared to non-Indigenous women. Due to this discrimination, I want to consider how suicidal ideation and poor mental health continue to be an issue for First Nations people, particularly women.

\section{Child Welfare of Indigenous Children}

Discussed in three of the articles, the theme of child welfare was expressed as a key factor to how families continue to be negatively impacted following the experience of involvement with child welfare agencies. The studies that I will be drawing attention to are the 
following: Ma et al. (2019), McKenzie (1997), and Blackstock (2010). Reflecting upon Ma et al. (2019), the researchers found that even though First Nation children encompass $2.5 \%$ of the child population, they make up 7.4\% of the child maltreatment investigations in Ontario. Furthermore, these statistics were three times higher than White children (Ma et al., 2019). Looking at McKenzie (1997), the researcher finds that because of the overrepresentation of First Nation children expressed in the former study (Ma et al., 2019), there was a need to develop culturally appropriate child and family service standards for this population. In McKenzie's study, the researcher took it upon themselves to design and implement such appropriate services, thus fostering the result of differences and traditions being recognized as well as strengthening the relationship between child welfare services, band chief and council (1997).

Lastly, the study by Blackstock (2010) was created for the purpose of tracking cases of First Nations children and non-Indigenous children involved with child and family services, in order to analyze data for those that have been reunited with family and those that remained in care. The results showed that families living in poor housing were graphically over-represented for both White and First Nations, as well as substance misuse frequently being stated as the primary reason for child removal (Blackstock, 2010). The key difference in Blackstock's study was that across most of their data, First Nations children were more likely to receive discrimination and have a lack of consideration given to culture than the non-Indigenous families were given (2010). I intend to draw from these studies in my paper as I want to highlight the impact of child welfare involvement in a First Nation family on suicide amongst their youth as a contributing factor to the high prevalence rates on and off-reserve. 


\section{Storytelling}

In the study by Lafontaine (1998) storytelling emerged as an important theme that I felt needed to be categorized in this discussion. In this study, the researcher takes a narrative approach that investigates the experience of a First Nations principal in dealing with the loss of students and of his own son to suicide (Lafontaine, 1998). The research draws from oral history interviews and the participant's accounts of how the public-school system has historically been failing First Nations students for years (Lafontaine, 1998); while the principal is reflecting on the specific years of his own experience, these failings have been happening for centuries. Through studying this principal's experience, Lafontaine gathered that the education system needs to make a stronger effort in meeting the specific needs of First Nations people and to decolonize the space that continues to reject their traditions and cultures since the IRS era (1998). Clearwater (2014) suggests that a decolonized space is a source of healing. Specifically, Clearwater (2014) states for it to be space that "facilitates change in the colonial mentality" (p. 16) for both nonIndigenous and Indigenous people and allows healing from the grief of trauma, oppression, dislocation, and generations of genocide. In LaFontaine's study (1998), the principal highlights that Indigenous children should not need to choose between their heritage and living in the Western world, but that their cultural identity is what will be the answer to First Nation survival and the issue of youth suicide. For the purpose of this paper, I believe that drawing from real experiences such as storytelling, helps to illuminate how severe the suicide crisis is amongst First Nation youth as well as how the trauma responses of losing someone close to suicide impacts the suicidality of that person. Storytelling is a particularly effective approach to research because I believe that drawing from real experiences provides a voice from those who are impacted by the suicide crisis every day. Furthermore, storytelling could allow individuals to share their personal 
experiences in the way they want to present it and possibly give the researchers a better understanding of the whole context.

\section{Strengths and Limitations}

I have considered the strengths and limitations of the presented themes in the literature, in relation to my research topic. In McQuaid et al. (2017) and Bombay et al. (2019), the authors discuss the theme of IRS. There are strengths present in both articles, as they are able to make the connection to how the experience of IRS has affected later generations in terms of suicidal ideations/attempts (Bombay et al., 2019; McQuaid et al., 2017). As this is a theme I may come across in my research, it is helpful for supporting the ideas that could be seen in the findings and something I may be able to expand on. Furthermore, the data pulls from only on-reserve populations, which is helpful for my research population focus. At the same time, drawing only from on-reserve statistics might be a limitation. For example, the studies do not consider how First Nations people living in northern Ontario and not specifically on-reserve have experienced IRS as well as its impacts (Bombay et al., 2019; McQuaid et al., 2017). Moreover, I do acknowledge that the studies also do not include the experience of those that are Inuit or Métis. However, for the purpose of my MRP, I am only focusing on First Nations people because of my experience working with First Nation youth and the unique experiences of First Nations living in northern Ontario communities, as I discussed in the introduction chapter.

In Elias et al. (2012) and Hamdullahpur et al. (2018), the authors bring up the theme of childhood sexual abuse and trauma. There are a few strengths when considering the studies. For example, both studies discuss how experiences of sexual abuse and trauma as a child increase an individual's risk for suicide (Elias et al., 2012; Hamdullahpur et al., 2018). This idea is helpful for my research as I am discussing specifically the influences within the youth suicide crisis. 
Furthermore, the studies address the experience of IRS sexual abuse being involved in suicide attempts later in life, which is a helpful for understanding how sexual abuse affects suicidality, but is also a limitation since this point does not specifically implicate the youth (Elias et al., 2012; Hamdullahpur et al., 2018). Another limitation is that the studies mention negative home environments and substance misuse as a community problem involved with childhood sexual abuse and trauma, but do not add in discussion on how the broader societal conditions are associated with this issue - for example, colonization (Elias et al., 2012; Hamdullahpur et al., 2018).

In Maranzan et al. (2011) and Dunn (2013), the authors discuss the discrimination of women. Both articles have strengths, as they discuss the topic of suicide amongst First Nation people, and particularly how suicidal behaviour has been seen more often in women than men (Maranzan et al., 2011; Dunn, 2013). This information is helpful for my research as I am able to consider the deeper influences for the suicide crisis amongst First Nation girls. In addition, another strength is when Maranzan et al. (2011) address how this difference between men and women is due to First Nation women experiencing greater social and economic inequalities than First Nation men. Considering the reasons behind greater suicide in women, it is useful for my research and drawing implications within the findings (Maranzan et al., 2011). There is a limitation found in this literature. For example, it is a limitation that the literature does not sufficiently consider what the experience may be for those who identify as transgender, 2-Spirit or other identities. In reflecting on this issue, I acknowledge that this research does exist but that much of the literature on transgender suicidality does not include First Nations in the descriptors or tags, even if it is addressed throughout the source. I believe that this is something to be addressed by authors and editors when manuscripts are finalized going forward, because 
otherwise these sources do not get captured in a literature search. In another limitation, I have noticed that the study from Maranzan et al. (2011) is limited in the way that they do not mention if these statistics are the same for the youth population.

Regarding child welfare for Indigenous children, the studies by Ma et al. (2019), McKenzie (1997), and Blackstock (2010) discuss this theme. There are strengths when considering the literature, as the data has found the overrepresentation of First Nation families involved in child welfare compared to White families to be implicated in the suicide crisis (Ma et al., 2019). Furthermore, Blackstock (2010), discussed the key factors of poor housing as well as lack of consideration to culture and racial discrimination associated with increased child welfare involvement in relation to youth suicide. Reflecting on Blackstock (2010), their key point is to increase awareness for social workers "regarding the importance of documenting the cultural backgrounds of all children" (p. 239) and to incorporate the cultural identity of children into child and family service plans. Considering the ideas brought forth through these studies, I hope that they may be useful in making later connections that expand or confirm the research findings. Reflecting on McKenzie (1997), the study is also helpful in the way that the author discusses future implications for child welfare and the need to develop culturally-appropriate services. Though the study does offer ideas regarding ways to address the child welfare problems, it is a limitation that the author does not discuss how the suicide crisis is directly impacted by these positive changes (McKenzie, 1997).

Reflecting upon the theme of storytelling, Lafontaine (1998) addresses this idea through their narrative study. Lafontaine discusses the experience of a First Nations principal who had lost students as well as his own son to suicide (1998). This study is valuable and shows strengths towards my research topic due to both drawing from a first-hand experience and directly 
addressing the suicide crisis amongst First Nation youth. Moreover, other strengths include the highlight of culture towards helping the suicide crisis get better as well as considering the idea of trauma and loss to suicide influencing suicidal behaviours in an individual (Lafontaine, 1998). One limitation of the study is where the author only discusses how the education system can improve to help First Nation youth, rather than considering the other political spaces where decolonization may need to occur.

\section{Paradigms and Theoretical Frameworks}

In the following section, I will be discussing several paradigms and theoretical frameworks found throughout the previous studies that the authors had used. Specifically, I will be addressing Indigenous paradigm, psychodynamic theory, feminist theory, Durkheim's sociological theory, and religious commitment theory. For the purpose of this literature review, I feel it is important to acknowledge these theories in order to understand how I can better approach my research as well as to properly critique, rather than accept each framework as valid for the context of my research. In going through the paradigms and theoretical frameworks, it will also help to identify what limitations and strengths exist.

\section{Indigenous Paradigm}

An Indigenous paradigm is described by Pidgeon as an "active form of resistance to the oppressive, colonial representation of the past that resulted in inadequate policy, methodology, and theoretical applications against Indigenous peoples” (2019, p. 422). Commonly used throughout several of the studies, an Indigenous paradigm was used as the central focus in carrying out the research. For example, research by Bombay et al. (2019), Ma et al. (2019), McQuaid et al. (2017), McKenzie (1997), Blackstock (2010), Maranzan et al. (2011), and Lafontaine (1998) all utilized this paradigm in their studies. In Bombay et al. (2019), McQuaid et 
al. (2017) and McKenzie (1997), the authors utilize Indigenous paradigm because they each discuss the importance of adopting culturally based programs regarding mental health and recognizing the ongoing systems of colonization. Ma et al. (2019) as well as Blackstock (2010) also utilize this theory, as they highlight the need for Indigenous concepts of child safety and wellness, over Western ways. Furthermore, this theory is used in Maranzan et al. (2011) due to their study focusing on issues with colonization and demonstrating the particular inequalities faced by Indigenous women, over those who are White women. Lastly, Lafontaine (1998) utilizes this theory, as the author emphasizes the unique needs of First Nations people and culturally-appropriate policy development in First Nation schools. Considering the purpose of my research paper topic, I believe that it is vital to acknowledge the particular worldviews for First Nations people and to situate my research through a decolonization lens.

\section{Psychodynamic Theory}

Another common theory that came up in the research was the psychodynamic theory. In the studies by Hamdullahpur et al. et al. (2018) and Elias et al. (2012), the researchers frame their work through this particular view in investigating the impacts of childhood experiences on an individual when they become an adult. Psychodynamic theory by Sigmund Freud "attempts to explain human behaviour in terms of intrapsychic processes...that are often outside of an individual's conscious awareness and have their origins in childhood experiences" (Deal, 2007, p. 185). In relation to suicidal behaviours in the contexts of Indigenous peoples, both the studies by Hamdullahpur et al. (2018) and Elias et al. (2012) utilize this theory as just one of the many ways to help understand the effects of childhood trauma. For example, the authors address in their studies the suicidality of an individual to be influenced by the abuse they have experienced 
in childhood and the psychological trauma that is carried as they age (Elias et al., 2012;

Hamdullahpur et al., 2018).

\section{Feminist Theory}

In the studies by Maranzan et al. (2011) and Elias et al (2012), the researchers utilize this theory as one of the ways they situate their research within a First Nations context and the specific struggles that First Nations women face. Explained by Turner and Maschi (2015), feminist theory emphasizes the discrimination women endure in status and power related to gender as well as the inequality in the social, political, and economic relations. Furthermore, feminist theory aims to reclaim power to bring about social change (Turner \& Maschi, 2015). In both Maranzan et al. (2011) and Elias et al. (2012), First Nations women are recognized as continuing to experience social injustice and ultimately, impacting the high rates of suicide attempts within this population.

\section{Durkheim's Sociological Theory}

Outlined in the study by Dunn (2013), the researcher highlights the use of Durkheim's Sociological theory in relation to factors of suicide. Dunn explains that this theory believes that suicidal ideation is impacted by the "disturbed regulation of the individual by society... either a disturbance in social integration or moral regulation" (Dunn, 2013, p. 8). In researching the decision-making process of suicide with First Nation youth, Dunn notes this sociological model is the most prominent amongst mental health research (2013).

\section{Religious Commitment Theory}

Drawing once again from Dunn (2013), Stack's Religious Commitment theory (RCT) is another positionality that the researcher utilizes. RCT is defined as the suggestion "that devotion to a few central religious beliefs, such as the belief in the afterlife...may be sufficient for an at- 
risk person to develop a defense mechanism against suicide” (Dunn, 2013, p. 9). Thus, Dunn stated this theory is important to consider in its contribution to the experience of suicide for First Nations people (2013). The author uses this theory throughout the research because he focuses on the participants experience with suicidal ideations and highlights the importance of their thoughts on afterlife if they were to complete suicide (Dunn, 2013).

\section{Strengths and Limitations}

I now reflect on the strengths and limitations of the theoretical frameworks and paradigms that informed the literature I have reviewed. I have listed those frameworks and paradigms above, but here I acknowledge that while there are many ways in which they are useful for my research paper topic, at the same time, the use of these frameworks and paradigms need more critical analysis. Starting with an Indigenous paradigm, I believe that all research regarding Indigenous peoples should consider this way of knowing as an active method of decolonization in academia. Understanding the historical oppression that Indigenous peoples have experienced and continue to experience every day, this paradigm provides an important situating framework that allows for their cultural and traditional values to be represented throughout research goals. Most importantly, knowledge produced through an Indigenous paradigm helps to resist the oppressive Western knowledge that is often dominating mainstream literature and creates the necessary dialogue needed for change.

Bringing attention to psychodynamic theory, there are strengths that come with using this theory for research on suicide. As defined previously, psychodynamic theory looks at how childhood experiences of trauma impact behaviours as adults (Deal, 2007). Relating directly to my research paper, this theory is powerful because, for example, it draws attention to how the effects of sexual abuse as a child is a factor for suicide attempts later in life. Feminist theory is 
also essential to consider within these studies and as it is related to suicide. Bringing in the needed discussion on how First Nations women experience domestic violence and sexual abuse more frequently than men, especially due to the intersectionality with racism (Farley et al., 2005), feminist theory helps to unpack these issues - which I will be tackling in more detail throughout my research paper. Lastly, reflecting on sociological theory and religious commitment theory from Dunn (2013), both offer insightful information into reasons why suicide may be a considerable option amongst First Nations youth. As sociological theory is explaining how society is implicated in one's decision making process for suicide and religious commitment theory is providing a motivating factor in desiring suicide (Dunn, 2013), I believe that they contribute to my research paper discussion quite well.

. Thinking about psychodynamic theory, sociological theory and religious commitment theory, it is helpful to notice that they are all Western positions that may do more harm than good for studies regarding First Nations people in Ontario. Specifically, it could perpetuate the colonial agenda instead of dismantling the structures that colonization has built over the years and oppressed Indigenous folks. Lastly, feminist theory has the potential to help support the research in this research paper, but it needs to be done through a decolonized mindset. If not, I fear that it leaves the possibility to only value the White experience and how White women are subjected to gender discrimination, rather than how First Nations women experience the same discrimination but on a deeper level due to racial identity.

In consideration to how these paradigms and frameworks may be limited, I also need to consider the potential of an Indigenous paradigm, which was largely missing from many of these sources. Despite the lack in these particular sources, an Indigenous paradigm was found included in some of the previous literature, such as Menzies (2010) who highlights a model of 
intergenerational trauma in historical processes of colonialism in the collection and evaluation of data. Furthermore, Kirmayer et al. (2003) is situated through an Indigenous paradigm, as the study is focused within the examination of collective trauma due to colonization influencing suicidality. I do recognize that for non-Indigenous researchers it can be problematic utilizing an Indigenous paradigm. It is not that this paradigm is limited in any way, but that as a nonIndigenous person, I do not want to risk the issue of appropriation when attempting to utilize Indigenous ways of knowing, such as in relation to traditions, values and culture. Furthermore, I understand the importance of relationship with Indigenous people as vital to the research process, where if the relationship does not exist, I believe utilizing an Indigenous paradigm can be problematic. For example, in Pidgeon (2019) the author states that an Indigenous-informed paradigm "emerges from the relationships of an Indigenous researcher with the Indigenous community" (p. 419). Moreover, that the research process is complex and this relationship to the Indigenous community is central to how the research will be conducted (Pidgeon, 2019). In recognizing these concerns and the relationship I have with First Nation communities in my personal and professional work, I have chosen to take on an Indigenous-informed methodology, but specifically through the concepts outlined in Kovach (2010)'s work.

\section{Conclusion}

Reflecting on the strengths and limitations of the literature, I have been brought to research the influences on the suicide crisis amongst First Nation youth in northern Ontario. Based on the wealth of literature regarding First Nation suicidality, I intend to explore in my research whether the issues regarding suicide have stayed the same or developed over time in our current society. 1. In recognizing the impact of cultural continuity and trauma on First Nation youth suicide, I am curious to uncover whether these influences are also seen in the findings and 
what differences there may be to the existing literature. By reflecting on one's relationship with culture and its continuity in a community, I am wanting to see how the findings discuss the influence of culture as an impact on suicide and suicide prevention. Furthermore, I want to consider the concept of trauma and the collective experience of trauma that was seen through the relevant literature to impact First Nation youth suicide. In the findings, I want to explore how trauma is addressed in relation to the suicide crisis and how this concept is the same or has developed. Through recognizing these factors as highlighted in much of the literature, it can be seen how important culture and trauma are to this topic. Thus, in researching 'The Influences on the Suicide Crisis amongst First Nation Youth in northern Ontario", my hopes are to discover how the findings may differ from or have stayed the same compared to what was found in the existing literature. 


\section{CHAPTER 3. THEORETICAL FRAMEWORK}

Reflecting on the purpose of this research paper, there are several theories that will be informing my topic on the Influences on the Suicide Crisis amongst First Nation Youth in northern Ontario. Specifically, I will be situating my research under an Indigenous paradigm that will include the use of decolonizing theory and appreciative inquiry theory. As the main overarching theory that will guide my research, I will be drawing from an Indigenous paradigm that is described by Pidgeon (2019) as an "active form of resistance to the oppressive, colonial representation of the past that resulted in inadequate policy, methodology, and theoretical applications against Indigenous peoples" (p. 422). Furthermore, Pidgeon continues to state that this paradigm utilizes Indigenous ways of knowing that values their unique culture, self-determination, and facilitates empowerment (2019). In understanding Indigenous ways of knowing, Pidgeon (2019) discusses how bringing in the concept of relationship is an important aspect of Indigenous knowledges, specifically recognizing and highlighting the "interrelationships of Indigenous knowledge that related to time being non-linear and the wholistic nature of self in relation to others" (p. 421). Moreover, Pidgeon (2019) states it is important to understand the Indigenous cultural and spiritual teachings as legitimate knowledge, rather than what the researcher feels is valid. ŁAs mentioned previously, being a non-Indigenous researcher reaching Indigenous issues does serve as a limitation to my MRP, as I cannot and do not feel as if I know more about Indigenous culture than a researcher who is Indigenous. However, because of my experiences as a mental health worker with First Nations communities in northern Ontario, I do not feel I can do this MRP without incorporating elements of an Indigenous-informed paradigm into the work. To do so would be doing what I already criticized as a limitation in some of the research I looked at in the literature review. Considering the 
purpose of this research paper, centering the core theories under an Indigenous paradigm would provide the most appropriate and comprehensive analysis of data. As mentioned previously, I intend to discuss two other theories that will be used throughout my research, such as decolonizing theory and appreciative inquiry theory as discussed below.

\section{Decolonizing Theory}

Kovach (2010) states that taking on a decolonizing lens as a theoretical position matters and needs to be embodied personally for researchers (2010). Furthermore, the author explains that this would mean decolonizing theory to be defined as revealing "the degree to which Indigenous knowledges have been marginalized within Western research processes" (Kovach, 2010, p. 110). Drawing from Smith (1997), the author discusses how using a decolonizing theoretical approach is effective in the way that it analyzes power differences between Indigenous and non-Indigenous people, provides hope to transform the colonial ways of knowing, and focuses on the need for Indigenous sovereignty. Furthermore, he states that this theory opens discussion on structural political changes as he addresses the importance of resistance against colonialism and the current colonial structures, as well as focusing in on Indigenous peoples finding victories in the struggles (Smith, 1997). For those particular reasons, Smith (1997) and Kovach (2010) believe that it is important to incorporate a decolonizing theory when conducting research regarding Indigenous people and under an Indigenous methodological framework. Through addressing the ways in which one can resist the practices instilled by colonization, it allows for significant growth and healing to occur in society for Indigenous people. 


\section{Appreciative Inquiry Theory}

In Kaminski (2012), the author describes appreciative inquiry theory as an approach that "selectively seeks to locate, highlight and illuminate the life-giving forces within an organization or community" (p. 1).”. Moreover, Kaminski states that the aim is to find what the best of a certain situation or factor is in order to kickstart a collective imagination of potentials, as well as generating new knowledge that is able to expand possibilities in hopes to help people imagine a desired future that can become reality (2012). Appreciative Inquiry Theory is valuable to my research because it is able to work together with decolonizing theory's concept of Indigenous under an Indigenous paradigm, sovereignty (Smith, 1997), through the collective potentials and resistance against colonial oppression. In addition, this theory discussed the importance of focusing on a problem-solving approach that identifies one's strengths as well as stresses making decisions through collaboration (Kaminski, 2012).

\section{Theoretical Approach}

In choosing an Indigenous paradigm that considers decolonizing theory and appreciative inquiry theory, I believe that my research on the Influences on the Suicide Crisis amongst First Nation Youth in northern Ontario can be delivered in the most suitable manner. Through keeping particular attention on the effects of colonization and how it has permeated research throughout history, I can utilize these theories to help decolonize the way in which my data is collected and presented. In decolonizing the collection and presentation of research data, I intend to focus heavily on the experiences and knowledges of First Nations people. By doing so, I am able to bring forth Indigenous ways of knowing and not give power to colonial knowledges that have marginalized Indigenous research throughout history (Kovach, 2010). Furthermore, by researching within the population of First Nations people, it does not make sense to center both 
theoretical framework and methodology under a Western lens due to the risk of doing more harm than good. Reflecting on my professional experience working with First Nations people living in northern Ontario, I believe that my personal epistemologies when working with clients is interconnected well with the mentioned theories. My professional experience is implicated with these two theories because I encourage a strength-based approach in my practice, as appreciative inquiry theory highlights identifying one's strengths through collaboration (Kaminski, 2012). Therefore, it is only fitting to situate my research similar to the way in which I carry out my professional work.

In connection to my reasoning for choosing decolonizing theory and appreciative inquiry theory in regard to an Indigenous paradigm, these theories work together significantly. As Kovach (2010) unveils in her writing, the fluidity of incorporating the two theories under a qualitative, Indigenous methodology allows for more reflexive and culturally appropriate research to occur. In addition, I believe that these specific theories are well connected as they inform one another in values. For example, the inherent focus on strengths and collaboration to reach a desired future of appreciative inquiry theory (Kaminski, 2012) falls in line with decolonizing theory's goal of transformation and allowing Indigenous people to find victories in their struggles (Kovach, 2010). Therefore, it can be understood that each theory works positively with the other. Furthermore, the two theories will be able to provide my research with a more comprehensive approach. In utilizing the concepts of power differences in decolonizing theory with collective resistance in appreciative inquiry theory for example, I can focus on the idea of Indigenous people reclaiming power through communal resistance. Thus, I believe that drawing from both theories will create more meaningful discussion on implications found in the findings chapter. 
Understanding how my theoretical framework has informed my research thus far, I believe that the inclusion of an Indigenous perspective is critical when reflecting upon my topic regarding First Nation youth suicide. The suicide crisis, within the particular context of First Nations people, is different from understanding a suicide crisis amongst the general or Western population in Canada. Additionally, my professional work has focused directly with this population living in northern Ontario, where I have experienced the frontline effects of suicide on the individuals I have worked with and their community. Due to the consistent encounters with this crisis, I have the passion to research deeper and to add to the existing knowledge through the use of an Indigenous perspective in my theoretical framework and methodology. Reflecting upon the methodology, discussed in the next chapter, the specific attention on Indigenous inquiry SDA coincides with the theories that I intend to situate my research through. Looking at the methods of data collection and analysis, they consider information that concentrate solely on Indigenous people in the Canadian context. Furthermore, the results of such data can be used to inform future suicide prevention strategies - as fitting with Kovach (2010) and Kaminski (2012)'s definitions of decolonizing theory and appreciative inquiry theory. 


\section{CHAPTER 4. METHODOLOGY}

In consideration to methodology, this research will be informed through a qualitative lens as the broader framework and be guided specifically through the use of secondary data analysis (SDA). Within SDA and understanding the research topic of this paper, the methodology is informed through an Indigenous inquiry, as derived from Indigenous methodologies:

Characteristics, conversations, and contexts (Kovach, 2010) and will be explained further in this chapter.

SDA is the model in which I am collecting research data for my topic on the Influences on the Suicide Crisis amongst First Nation Youth in northern Ontario. "Secondary data [is] information that has already been collected by someone else and is available for you, the researcher, to use" (Clark, 2005, p. 57) While SDA is often done with quantitative data from a different research study, it is not limited to quantitative research. "Secondary research is an investigation using evidence or data that have not been collected by the researcher but rather produced by someone else for another purpose" (Barker \& Alldred, p. 141). Furthermore, Sales et al. (2006) discuss how SDA has the ability to answer various questions in research that have descriptive, explanatory and exploratory objectives.

In direct relation to my research topic, Sales et al. discuss how the emergence of SDA first was seen in Durkheim's research on suicide and is referred to as an early example of this methodology being employed (2006). Reflecting on youth suicide amongst First Nations people, SDA in this context is a useful tool in collecting data throughout the research process, but doing so in a way that explores the issues without retraumatizing First Nations people by asking them to yet again share their experiences. In being specific with the type of methodology, I am conducting my research by focusing on generating new knowledge based on pre-existing data 
from two documentaries and one news episode published online that are made publicly accessible. I have no recruitment method due to the fact that there are no human participants involved.

I am also limiting my research to these three sources, as using too many sources may overwhelm the amount of data within the constraints of this MRP and too little sources could create concerns where there is not enough data. In finding these sources, I had searched online for documentaries that specifically discussed First Nation youth suicide occurring in northern Ontario. In the search for data sources, I was able to find two documentaries that were situated in this context: Cut-Off (Gallagher \&Williams, 2016) and Back to Pikangikum (Rajotte, 2004). After exhausting the search for all relevant documentaries, I was also able to find the 40-minute news episode, “Confronting Suicide Among Canada’s Indigenous Communities” (2016). I am specifically using documentaries and news sources as data because I believe that they will best help me gather findings from individuals who have experienced the suicide crisis and speak personally about it, rather than choosing to read about an individual's story that other sources may provide. "Documentary has a distinctive relationship to the circulation of public knowledge and therefore to issues of power - its reinforcement or questioning - that has been a recurring subject of critical analysis" (Nash \& Corner, 2016, p. 229). News stories are useful sources of data for analysis related to social issues, especially those issues that are "relatively 'invisible' and less palatable" such as youth suicide (Roberto et al., 2013, p. 231). Therefore, these three sources of information are the sources of data I am using, as a form of secondary research for my data analysis. These sources form secondary research because I am gathering the presented quotes and stories that have already been collected for public consumption, but now I am doing SDA of these sources in order to connect themes and create possibility for new meanings to be 
drawn from the data, regarding my research topic. I believe that the use of this particular methodology is valuable to my research in several ways; I am able to draw new ideas from the existing data in relation to my topic, re-examine various ideas and perceptions in a new way, and consider implications towards better services and policy for First Nation communities dealing with a suicide crisis.

Furthermore, the methodology I am using to inform my research draws from an Indigenous perspective that is outlined in Kovach (2010). Kovach addresses methodology in research with particular attention in how to appropriately study topics that are about or for Indigenous peoples, which is the focus of my MRP. While I am discussing the influences on suicide with First Nations youth, I believe that it is important to inform my work from a perspective that acknowledges and respects their cultural worldviews. Therefore, my research draws from Kovach (2010)'s relational approach within Indigenous inquiry. A relational approach is explained as understanding that qualitative research is relational in nature as well as suggesting that there must be an ongoing relationship between the researcher and the research that is being done (Kovach, 2010). For example, it is important to highlight my personal relationship in terms of why I am researching First Nation youth suicide and how I am implicated as a non-Indigenous person researching this topic.

As a non-Indigenous researcher, I recognize the concern with researching a topic that is about Indigenous people. Furthermore, as how utilizing an Indigenous paradigm as a nonIndigenous person is limiting in the relational aspect to Indigenous communities, as discussed previously. In Kilian et al. (2019), the authors discuss how throughout history, many nonIndigenous researchers had conducted the majority of research for and about Indigenous people. Moreover, that much of the research rarely had direct benefits and sometimes resulted in harm 
for Indigenous communities (Kilian et al., 2019). Thus, I understand the risk of harm that can be done to communities where there is data created that does not highlight an Indigenous voice nor the voice of their community. Furthermore, I realize how that issue could silence many Indigenous researchers already doing similar studies but not getting the attention they deserve. With this understanding, I still have chosen to explore this research topic because of the personal impacts the suicide crisis has had in my life and the goal within my research to highlight as many Indigenous voices as possible, rather than my own voice. In spite of the concern of nonIndigenous researchers researching on Indigenous issues, I want to explore the suicide crisis not to advance myself but in order to comprehend how I can better support my Indigenous friends, clients, coworkers, and specifically youth going forward. Similar to what was address previously, in also utilizing an Indigenous paradigm, I do not intend to insist that my knowledge is valid, but to respect Indigenous culture through the use of their voices and what the community states are issues for them, as Pidgeon (2019) addressed. Furthermore, the reason I believe relational approach is appropriate and why I research this topic as a non-Indigenous person, is due to my professional experience working with First Nation youth in remote communities. As I encounter experiences with suicide frequently in my mental health worker position, I believe I have a strong relationship to this issue. I have experienced loss to suicide from a professional standpoint, as there was an individual with whom I had built a relationship who ended their life by suicide. Furthermore, I have witnessed and interrupted suicide attempts of youth at several points in time which had led me to understand how large an issue it has become. Due to these reasons, I now have a relationship with the community through our mutual relationship and connection to suicide. Therefore, I believe it is important to adopt a relational approach, and out of respect for those relationships I have, I am not using human participants. 
In qualitative research, the relational approach is also concerned with including discussion on colonial relationships and decolonization, especially when Indigenous knowledges are introduced into academic discourse at any point in time (Kovach, 2010). Additionally, Kovach explains that throughout the use of this methodological stance, it stresses the importance of reflexivity as relationality is rooted in the idea that a researcher must have their "own selfreflection in the meaning-making process" (2010, p. 51). By understanding the concept of reflexivity, I reflect on my personal experiences, identity and relation to the First Nation youth suicide crisis on a meaningful level.

The reason I have chosen SDA through an Indigenous inquiry is due to the personal connection I have within my professional work experience and due to respect for those relationships built. As I have personal implications to this topic due to the relationship with the suicide crisis discussed in the previous section, I believe SDA can help to mitigate any harm caused by using human participants. I will discuss what this harm would be later in this section. In addition, I have noticed that there is much existing research about Indigenous peoples and about their issues but less research that actually talks to Indigenous people. I believe that if research does not use the voices of Indigenous people, the perpetuation of stigma and the specific problems they face will continue. That is also why I have chosen SDA and specifically sources that draw on the first-hand experience of First Nations people living in communities dealing with the suicide crisis.

I acknowledge the ways in which SDA) can be harmful. In Sales et al. (2006), the authors discuss how SDA could cause a researcher to be less aware of failings, errors or biases in the existing data due to unfamiliarity of the primary data procedures. For this reason, a researcher may overlook these issues, risk perpetuating the same problems in their own study, and be overly 
confident that the data is accurate (Sales et al., 2006). In the context of First Nation youth suicide, this may look like assuming negative biases about First Nations people that could do more damage than good, especially with the sensitivity around suicide. Furthermore, Sales et al. (2006) states that SDA can cause researchers to be limited in finding new ideas and themes from the data. Specifically, the research analysis can be constrained within the existing questions that can be explored, as SDA pulls from data already documented (Sales et al., 2006). Due to this limitation, it may inhibit my research from obtaining new knowledge and meaning to how suicide is currently affecting youth in northern Ontario First Nation communities.

Despite these limitations, I believe that SDA does fit with my research topic and is appropriate in this context. As stated previously, I believe the use of this methodology will limit the risk of harm that comes with using human participants. In Sales et al. (2006), the authors address this concern and why SDA is a useful methodology. For example, Sales el al. address the issue of human participants, specifically those that are a part of vulnerable groups, such as people with mental disabilities or abuse victims (2006). Furthermore, the Sales et al. state that by "using previously collected data, the research avoids intrusiveness of data collection, as well as the possibility of inflicting harm to [these] vulnerable groups (2006, p. 549)". Therefore, I argue that SDA works for my research because I am dealing with the vulnerable population of youth suicide and in order to avoid inflicting further harm or mental distress.

The reason I have chosen this research topic is greatly due to my professional experience, as mentioned before. During my time working in this field of social work, I have personally witnessed the effects of suicide on the communities I have worked with and have lost my own clients to suicide throughout my life. Based on the systemic inequalities I have experienced when attempting to support the communities, my experiences have informed the desire to bring forth 
the current oppressions that influence the suicidality of an individual and ways it can be prevented. Understanding the current data, Eggertson (2015) discusses how the suicide rates amongst First Nation youth have tripled since 1991 for remote, northern Ontario communities and have statistics 5-6 times higher than those who are non-First Nation. Therefore, drawing from the recorded data and my experience working with this population, I aim to use this major research paper as a way to shed light on a serious crisis that has impacted not only myself, but the communities I have supported throughout my social work career.

Reflecting upon data collection methods and analysis approach, I am situating my research through SDA which consists of collecting data through publicly accessible online sources based on information directly related to my topic on the Influences on the Suicide Crisis amongst First Nation Youth in northern Ontario. Considering my data analysis approach, I will be focusing on themes that emerge amongst the research gathered based on the influencing factors of suicide amongst First Nation youth. Furthermore, I will be highlighting how those themes may be influencing factors to the current suicide crisis. By conducting data analysis through looking at particular themes, I will be able to draw what the influences on suicide may be in hopes to provide another perspective that acknowledges First Nation suicide as a product or symptom the of cultural, biological and physical oppression that has historically affected their community for decades (Fontaine, 2016). Moreover, by drawing connections between different influences on suicide, I believe new dialogue can be created for future discussions on policy and to recognize the intersectionality that affects this specific population in my research. 


\section{CHAPTER 5. FINDINGS}

Through a detailed analysis of the results found using SDA on the Influences of the Suicide Crisis Amongst First Nation Youth in northern Ontario, the data has shown several themes that highlight many important and different aspects of my research topic. Over the course of this chapter, I divide the results of the data analysis into categories based on common themes or ideas found in the research. Under each of the themes, I include a brief background regarding that specific commonality and then incorporate the relevant findings, followed by a discussion.

Throughout this chapter, I want to make note that I choose to use the term "completing suicide", instead of "committing suicide". This is due to my personal concerns in trying to understand suicide with terms that can appear to criminalize suicidal behaviour, particularly in this context of First Nation youth. Therefore, I have chosen to replace the word "committing" with "completing" in order to avoid the negative connotation that may be associated with the latter and could put blame on individuals rather than suicide being a political crisis.

\section{Sources of Information}

In considering SDA, I had chosen two documentaries and one news interview episode that address the First Nation youth suicide crisis in northern Ontario communities. At the start of gathering the data for this MRP, I already knew that there would be many valuable documentaries and interviews to choose from due to my exposure of their existence in my professional work. After researching and engaging with the documentaries and news interviews I knew and those I had not known of until this point in time, I decided to utilize the following three sources: Cut-Off by Gallagher and Williams (2016), Back to Pikangikum by Rajotte (2004), and news episode “Confronting Suicide Among Canada's Indigenous Communities" (2016). 
The reason I have chosen these three sources is because of the extensive analysis into suicide amongst First Nation youth that they provide, in which deeper and more detailed layers of influences involved in the suicide crisis are discussed thoroughly by community members, narrators and interviewers.

Reflecting on the three data sources informing my MRP, each source provides first-hand accounts from First Nations people living in northern Ontario reserves as well as the commentary from narrators and interviewers. For my analysis, I began by exploring all community member voices that spoke about issues related to my topic. In this way, I sought to centre the voices of community members wherever they were present. I then have brought in narrator and interviewer quotes into my research in several areas, as they addressed several of the issues that community members are facing in relation to the youth suicide crisis. In addition, the commentators in particular have collected stories from many community members as part of their work developing the documentaries and news story, and in doing so, have provided a compilation of those voices. Therefore, I have chosen to bring in the voices from these compilations as well. Furthermore, I have only included the voices of Indigenous commentators. I have done so to prioritize utilizing the voices of First Nations people and community members as key sources of information to address in my research wherever possible.

In the following sections, I outline multiple themes that I have gathered and noticed in my analysis of the three sources.

\section{Lack of Access to Resources}

Across the data, there has been a common theme of access to resources and the lack

thereof. Interestingly, each of the data sources discuss this issue to a large degree and relate it as an influencing factor into the youth suicide crisis amongst First Nation communities in northern 
Ontario. Furthermore, the data has paid attention to the particular resources of education, housing, health care and mental health services, as well as the availability of clean water provided to communities.

In Cut-Off (Gallagher \& Williams, 2016), Indigenous host, Sarain Carson-Fox, travels to Shoal Lake 40 First Nation. Shoal Lake 40 sits directly on the border of Manitoba and Ontario in Canada, home to a community impacted by suicide and struggling with little accessible resources (Gallagher \& Williams, 2016). Sarain Carson-Fox addresses this idea and states, "when you are a member of a community that doesn't have any access to basic necessities, you feel like you are less than" (Gallagher \& Williams, 2016, 7:25). Furthermore, Sarain adds:

It's like being in a prison in general population, and then you have some communities that just keep getting put in the hole. They just keep getting put in isolation and they're just given exactly enough to survive, and it's perfect. It's a perfect scenario because eventually if you stay in that scenario long enough, you start killing off yourselves. And then you're not a problem for the government anymore. (Gallagher \& Williams, 2016, $7: 44)$

In discussing lack of resources, Sarain highlights that due to the prolonged endurance and isolation in poor living conditions for First Nations people in northern communities, many youth end up taking their own lives (Gallagher \& Williams, 2016).

Drawing from Back to Pikangikum (Rajotte, 2004), the documentary brings in another factor in relation to the theme of access to resources, such as lack of clean drinking water in First Nation communities. For example, Rajotte discusses the concerns in the community of Pikangikum, stating “it's summer and large, biting black flies are everywhere...homes here do not have indoor plumbing. Water is hauled from the treatment plant and the outhouse. Summer 
or winter, is the norm" $(2004,11: 05)$. Similar to what is mentioned in Rajotte's documentary, Gallagher and Williams (2016) also discuss the water crisis that affects the people of Shoal Lake 40. For example, Sarain Carson-Fox states that "without a water supply of their own, Shoal Lake 40 has been on a boil water advisory for 20 years" (Gallagher \& Williams, 2016, 14:32) and that as "you turn on your taps, the only water that is going to come out is contaminated. Because of that, bottled water needs to be delivered to every single resident of the community" (29:00). In analyzing this data, it is heartbreaking to discover the reality of the common issue that is occurring across First Nation communities, where many families do not receive the same access to the water that many Canadians can easily get from their own kitchens at any point in time. In the news episode "Confronting Suicide Among Canada's Indigenous Communities" (2016), several Indigenous scholars discuss the state of emergency that was called by Chief and Council in Attawapiskat First Nation. One of the issues brought up by Indigenous writer, Julian NoiseCat, is in regard to the water crisis in First Nation communities. Julian states:

I think that there's sort of a myth that is perpetuated, particularly on the political centre and political right that First Nations are some sort of sinkhole for government spending... as I mentioned, the $2 \%$ spending cap that existed until very recently, actually didn't even match the population growth amongst Aboriginal communities. So, we were getting less funding per person per annum... First Nation's children receive 30\% less funding than Canadian children throughout Canada. You go to any of these communities and it is plainly obvious that it would not be okay for a kid in Toronto to be living without clean drinking water, whereas that is okay in over almost 90 First Nations communities across Canada. So, I think there are very obvious wrongs. ("Confronting Suicide Among Canada's Indigenous Communities...”, 2016, 22:19) 
In this quote, Julian responds to the idea that Medical Anthropologist Gerald McKinley, has raised when he discusses the suicide crisis. Gerald states, "whenever people ask what the solutions are going to take, one of them is definitely structural changes, that are going to take money” (“Confronting Suicide Among Canada’s Indigenous Communities...”, 2016, 21:40). Therefore, drawing from the discussion on lack of access to water, both Julian and Gerald highlight how funding is involved and has been an influencing factor within the youth suicide crisis. In continuation of Julian's ideas, Gerald later adds:

"Suicide is a problem, but it's also an expression of other problems... of the violence, of the poverty, of the lack of access to food. So, without making those large-scale structural changes and returning autonomy to the communities, we're not going to get very far...”. (“Confronting Suicide Among Canada’s Indigenous Communities...”, 2016, 28:22). Reflecting on the presented data, I have noticed that there is much discussion on funding and its impact in relation to accessing resources throughout each of the data sources. For example, Chief Quill of Pikangikum addresses the issue in which the government had taken away his community's control over their own finances and placed responsibility on the community for their high number of suicides (Rajotte, 2004). Chief Quill states, "I feel like I wasn't given a fair chance to like, work on my community. Cause these are one of the things that Indian Affairs mentions was a social problem. But, how can I work without funding? How can I work with my community without any funding?” (Rajotte, 2004, 41:50). By not having financial control nor funding, this concern highlights that money can be considered a valuable resource that is needed to fund support programs when dealing with crisis - specifically, a suicide crisis in this context. After speaking with the Chief of Pikangikum, Coleen Rajotte shares about the three suicides happening in the community, just from the time when they began filming the 
documentary (2004). Rajotte states, "three young girls. Two only thirteen years old take their own lives. The fact that young girls are being lost is described as a national crisis. While the government thought taking away financial control would lead to healing, the opposite has occurred" $(2004,43: 07)$. By analyzing these series of quotes, it is shocking to understand how great of an impact little access to resources has taken on Pikangikum First Nation in such a short period of time.

As another resource that many Canadians are granted access to, education in First Nation communities has also been a topic of interest brought to light in each of the documentaries and news episode. Discussed in Gallagher and Williams (2016), Sarain Carson-Fox tells the viewers of Shoal Lake 40's struggles regarding education. Sarain states,

Shoal Lake 40 does not have a high school. After Grade 8, teens must move away to nearby cities to continue their education. It means that at a very young age, you have to leave your family and leave your community and deal with an entirely new experience that could potentially put you in danger. (Gallagher \& Williams, 2016, 32:58).

Reflecting on this quote, one can see the reality of the high school experience for First Nation youth. Sarain stresses in the documentary that because of the lack in secondary education in northern Ontario communities and the dangerous situations of attending high school elsewhere, many youth have to risk their lives by pursuing further education (Gallagher \& Williams, 2016).Moreover, Sarain believes that this lack in secondary education on reserves influences the suicide crisis because it separates many youth at a young age from their family, from the safety of their home community, and from the supports they may have (Gallagher \& Williams, 2016). In "Confronting Suicide Among Canada's Indigenous Communities" (2016), Member of Parliament, Charlie Angus, elaborates on this issue in a featured interview and states, "if these 
were non-Aboriginal children, all the resources would be in their schools. When they're Aboriginal children, well hey, you can take a number and stand in line. And meanwhile, kids are dying every day" (1:43). Spoken powerfully, Charlie's words express to viewers how little the educational resources are amongst Aboriginal communities, in the context of the First Nation youth suicide crisis (“Confronting Suicide Among Canada’s Indigenous Communities...”, 2016).

Within the discussion on resources, Jocelyn Iahtail of Attawapiskat First Nation responds to a comment made by Gerald McKinley, in terms of availability of mental health supports in northern Ontario (“Confronting Suicide Among Canada’s Indigenous Communities...”, 2016). During the news episode, Gerald comments that there many services available to people and Jocelyn responds,

I just wanted to add to the comment that there's a lot of services. Actually, my experience is the opposite of that. I had to go outside of Canada to get the services I needed. As I stated, as surviving suicide and surviving incest and sexual abuse and the political violence that comes out of that from my own Indigenous community, I had to leave the community... and that suicide attempt at 15 catapulted me to get counselling. I went on to Minneapolis, Minnesota into a 28-day program for women that have been sexually abused as children.....and so, while we have alcohol and drug treatment facilities, we don't have enough programs directly dealing with incest and sexual abuse. It's a taboo subject...nobody wants to touch it. ("Confronting Suicide Among Canada's Indigenous Communities...”, 2016, 25:21)

Jocelyn raises a valuable point through sharing her experience because she addresses how the lack of access to resources has affected the suicide crisis in her community, as there are not 
enough programs and services for youth to access support ("Confronting Suicide Among Canada’s Indigenous Communities...”, 2016).

I believe sharing the words of Sarain Carson-Fox in Cut-Off (Gallagher \& Williams, 2016) ties up this theme on lack of access to resources significantly. Sarain expresses that, Reserves were created to disconnect Indigenous people from mainstream culture. They're cut off from access to basic human rights and things that other Canadians take for granted. Things like access to clean water, access to proper schooling and housing. So, you're also cut off from the basic necessities that allow you to feel connected, not only to yourself or your community, but to the rest of society, to Canada. (Gallagher \& Williams, 2016, 12:03).

Drawing from Sarain's quote, I believe she was effective is describing the common ideas that was addressed across the research data, in regard to the access or lack of access to resources and its impact on the suicide crisis amongst First Nation communities in Ontario.

\section{Indian Residential Schools and Intergenerational Trauma}

Throughout the data, the common theme of IRS was discussed in both documentaries and the news episode. In particular, the data had addressed the impact of the IRS system on the suicide crisis amongst First Nation youth. Furthermore, the data had also brought in some discussion on the idea of intergenerational trauma in relation to what was experienced in history and how that is affecting First Nation families today.

Reflecting on the data shown in the documentary, Cut-Off by Gallagher and Williams (2016), IRS was explored as a major topic for the community of Shoal Lake 40 and their suicide crisis. For example, an Indigenous mental health worker, Leonard Ross, states "in history, we were very peaceful people at one time, and then when Residential School arrived, that's when 
everything went...went chaos" (Gallagher \& Williams, 2016, 20:50). In focusing on Leonard's perspective, I believe it is an important insight into the current suicide crisis because this quote implies that there had been a time that life for First Nations people was good and healthy, until the point of IRS where that changed and suicide had become an increasing issue (Gallagher \& Williams, 2016).. Adding onto this discussion, community member, Stewart Redsky, shares what it was like for him as a child:

So, probably about 1968 ...I must have been around 8 years old. And I call it, 1968, as literally being in hell. I remember being physically taken in the Greyhound bus depot, riding away from the town of Kenora, not knowing where I was going. We cried and we cried until we finally came to our destination, the dreadful name of Shingwauk Residential School. I remember being processed there and being separated from my other two siblings. Asking yourself, 'Where's my mom? Where's my dad? Where's my brothers?'. It seems like there was already someone waiting for me and my brother at the residential school. We got so...so abused. It was a place of transformation for me. Family no more, it was. (Gallagher \& Williams, 2016, 22:28).

Stewart's testimony is an important quote to highlight when understanding how this experience affects the current youth suicide crisis. It is important because he explains in the documentary how the impacts of IRS had caused the loss of familial relationships to occur and that the youth involved in the suicide crisis today are individuals who do not have healthy family relationships to turn to for support (Gallagher \& Williams, 2016). Adding on to the discussion, Sarain Carson-Fox addresses its connection to youth suicide today. She states, Thousands of children were sexually abused at the hands of priests and nuns within Residential schools. Those children were released from those schools without any help or 
resources to deal with what had happened to them, and then they were asked to live a normal life and to contribute to society like all the rest of Canada. Those people became the parents of the youth we are seeing today, who are committing suicide. (Gallagher \& Williams, 2016, 23:39).

Reflecting upon Sarain's quote, she addresses a significant idea when she talks about how the First Nation youth that are completing or attempting suicide today, are the children of parents and grandparents that had attended IRS (Gallagher \& Williams, 2016).

Analyzing the documentary, Back to Pikangikum (Rajotte, 2004), the theme of IRS is briefly talked about as well. For example, Coleen Rajotte explains within the conversation of First Nation youth suicide that "in the early 1900s, all across Canada, children were forcibly removed and sent to Residential schools. Their culture traditions were banned, and assimilation was the goal" (2004, 23:05). The links between the impact of being in IRS, family trauma, and youth suicide is noted throughout the three sources, and reinforced by Rajotte's comments. In the news episode, Confronting Suicide Among Canada's Indigenous Communities (2016), Jocelyn Iahtail from Attawapiskat First Nation discusses her point of view on what IRS has done throughout her life in relation to youth suicide in her community. Jocelyn states, We can't just speak to the recent suicide attempts and the recent completed suicides, but the fact that this has been happening all my life. 70's, 80's, 90's, 2000's, right up until 2016. We need to look at the root causes. We need to take a look at the fact we have the Indian Residential School. That is the source of all this intergenerational trauma. Those of us who attended the Indian Day School right within the community of the Attawapiskat First Nation. These are the issues that we need to bring forward. The fact that we have professional individuals who've been in the frontlines working as 
counsellors and social workers. ("Confronting Suicide Among Canada’s Indigenous Communities...", 2016, 4:18).

It is interesting to notice that Jocelyn brings up the concept of intergenerational trauma, which is a part of the experience for First Nation's people related to IRS that was not discussed in Rajotte (2004) and Gallagher and Williams (2016), the other two sources I used as data for this MRP's data collection and analysis (“Confronting Suicide Among Canada’s Indigenous Communities...”, 2016). Reflecting on why intergenerational trauma is specifically referred to in this data source and not in the other two, I believe it could relate to different ways of speaking about the same concept. For example, when Sarain discusses the severe abuse in IRS and that the children that had attended became parents to the youth today who are completing suicide (Gallagher \& Williams, 2016).

In the same conversation on intergenerational trauma, advocate for Indigenous rights, Nicky Young, also talks about this idea and IRS in the specific context of the First Nation youth suicide crisis (“Confronting Suicide Among Canada’s Indigenous Communities...”, 2016). Nicky states,

This epidemic has been going on due to, you know, intergenerational trauma, due to resource extraction, due to residential schools. The suicides continue to mount, and Justin Trudeau is not doing anything really. The children of Attawapiskat have asked to meet with him, and he is completely ignoring that request. This is a Prime Minister who appointed himself as the Minster of Youth. This is a Prime Minister who was elected on a basis of starting a new relationship with Indigenous people. And the folks here have a resolve to stay here until Justin Trudeau addresses the issue. ("Confronting Suicide Among Canada's Indigenous Communities...”, 2016, 6:01) 
In Nicky's quote, he highlights the concern with how First Nation youth suicide is being influenced by numerous factors, such as the IRS system, and expresses his frustration to how he feels the Prime Minister of Canada needs to address such concerns ("Confronting Suicide Among Canada's Indigenous Communities...”, 2016). In comparison to the presented data thus far, I have noticed that Nicky had been the only one to describe the suicide crisis in this light. Within the same topic, Julian NoiseCat, also shares his thoughts in response to Nicky. He states, There's are a number of things going on here, I think it is not just a northern issue, it is not just a remote or rural issue, these are issues that happen across Canada. Cause across Canada there's a common history of colonization and settlement. This is a country that was founded on the dispossession of Indigenous nations, of the abuse of Aboriginal children in Residential Schools... and when you say these things, people...their eyes kind of glaze over and they say 'oh, well you're talking about things that happened 150 years ago'. But in fact, the Residential schools stayed open until 1996...these are communities that it's been totally fine throughout the history of Canada for them to have their children taken away, their land taken away and then to live in third world conditions.

(“Confronting Suicide Among Canada’s Indigenous Communities...”, 2016, 10:30). Considering the research sources, the theme of IRS and Intergenerational Trauma had been commonly seen across all the data. In both documentaries and the news episode, I found that many of the individuals I quoted had discussed this issue in detail and were able to relate their own personal relationships at the same time.

\section{Grief and Loss}

The theme of grief and loss in relation to First Nation youth suicide was frequently seen throughout the research, appearing both in the personal experiences of individuals as well as 
topic discussions. The topic of grief and loss was addressed across the data as common experience that many of the community members living in Shoal Lake 40 First Nation, Pikangikum First Nation and Attawapiskat First Nation had experienced (Gallagher \& Williams, 2016; Rajotte, 2004; “Confronting Suicide Among Canada's Indigenous Communities...", 2016).

In Cut-Off (Gallagher \& Williams, 2016), Indigenous host, Sarain Carson-Fox discusses the reality of grief and loss for many people living in the community of Shoal Lake 40 . Sarain states, "Everybody knows everyone, which means everyone knows someone who has lost someone. And everyone knows someone who's died... Before our crew arrived that day, there were four more suicide attempts in the community" (Gallagher \& Williams, 2016, 5:34). Reflecting on this quote, it is shocking to hear how often the experiences of losing someone to suicide can be in this community (Gallagher \& Williams, 2016), whereas many people may not ever have to go through it. In sharing her own story, Sarain says,

I understand the suicide epidemic within Indigenous communities from a very personal perspective. When I was 15, my dad, Roger Carson-Fox, committed suicide. Well, it changed everything for me. It changed my life, and it created this feeling inside of me that I was never really able to fill. So, I think for me, when I see these youth and I hear about youth suicide in our communities, I understand that most of them have probably already experienced suicide. (Gallagher \& Williams, 2016, 17:04).

Following Sarain's story, several community members of Shoal Lake 40 had decided to share about their experiences with the suicides in the community. One youth states, After I lost my three friends, I didn't feel like I could do anything. Every day I tired killing myself, but I never succeeded. And then I started talking to one person about my 
problems and I thought I didn't have anybody to talk to. Completely nobody, like nobody understood. (Gallagher \& Williams, 2016, 17:55).

In a later segment of the documentary, another youth opens up about their experience after losing their best friend to suicide in the community and how that had impacted them (Gallagher \& Williams, 2016). They state, There [are] two sides to me. There's this one side, this good side where I'm always happy, put on a smile every day just to make other people smile. But there's another side, the bad side. Sometimes I'd wake up and I would want to hang myself. I'd wake up to liking it. Then it started becoming stronger, and I started to love the thought of it, [be]cause I wanted to see how many people really cared for me. (Gallagher \& Williams, 2016,19:20).

In thinking about the presented data, it is important to recognize the voices of First Nation youth in my research, as they are the population directly implicated within the youth suicide crisis. Through reflecting on this youth's experience to losing a best friend to suicide, I notice how his grief and loss had impacted his own well-being. Specifically, this quote demonstrates how his loss to suicide had then influenced suicidal thoughts to occur within himself (Gallagher \& Williams, 2016), which both relates and is an example to the current youth suicide crisis. Looking at the documentary, Back to Pikangikum (Rajotte, 2004), a police officer, who is also a member of Pikangikum, discusses how the loss to suicide has impacted people in his community. He says,

There's a lot of our people here that still hurt over loss of loved ones. They hold on to this pain that they won't forget...it's hard to forget. There should be help to let go of the lost 
ones that they lost. They talk about their lost one that they lost while they are drinking. (Rajotte, 2004, 32:00).

Understanding the police officer's words, it is significant to see how grief and loss to suicide has affected so many people in First Nation communities across northern Ontario (Gallagher \& Williams, 2016; Rajotte, 2004; “Confronting Suicide Among Canada’s Indigenous Communities...", 2016). In the words of Coleen Rajotte, it is saddening to know that "every graduating student has lost someone close to suicide. Sadly, no one understands the need for change better than these students do" (Rajotte, 2004, 37:08).

Lastly, the theme of grief and loss is also present in the news episode, Confronting Suicide Among Canada's Indigenous Communities (2016). For example, having lived in a community that has dealt with many losses to suicide throughout history, Jocelyn Iahtail states, “If I may...I'm a suicide survivor. I attempted suicide when I was 15 [years old]”. Reflecting on Jocelyn's words, I believe it takes courage and is important that she shares her experience with suicide because it may encourage other Indigenous people to open up about their stories as well and help to better accurately discuss the suicide crisis ("Confronting Suicide Among Canada's Indigenous Communities...”, 2016). Furthermore, I value and appreciate the individual and collective stories of First Nations peoples to shine through.

\section{Connectedness to Land, Spirituality and Culture}

Regarding the last theme, I had recognized that the topic of one's connectedness to spirituality and culture was discussed throughout the research data as an important influence addressed within the suicide crisis amongst First Nation youth (Gallagher \& Williams, 2016; Rajotte, 2004; “Confronting Suicide Among Canada's Indigenous Communities...”, 2016). In understanding why land, spirituality and culture are in put into one theme, in both documentaries 
and the news episode the concept of spirituality and culture were often addressed with relationship to the land (Gallagher \& Williams, 2016; Rajotte, 2004; “Confronting Suicide Among Canada's Indigenous Communities...", 2016). Furthermore, this theme found in the data sources discusses the way in which land, spirituality and culture had been taken away from First Nations people and has affected youth today who are attempting suicide (Gallagher \& Williams, 2016; Rajotte, 2004; “Confronting Suicide Among Canada’s Indigenous Communities...”, 2016).

In Cut-Off (Gallagher \& Williams, 2016), community member, Daryl Redsky, talks about how the connection with his ancestors were disrespected when construction companies had ripped up the soil on sacred land. Daryl states, "this whole area that you see all the no trespassing signs, this is our homeland, this is where...this is where we lived" (Gallagher \& Williams, 2016, 14:54). Furthermore, Daryl explains

I have an old map that indicated our settlement and our burial grounds and exactly where that spot is, where we were living and where our ancestors are buried, is exactly what was all excavated and removed.... You have to remember all this happened in the 1990's...in order for them to take the water for the city, they expropriated 33, 000 acres of our land. (Gallagher \& Williams, 2016, 15:36).

Through the removal of sacred land, Daryl has highlighted the idea where this is simply another act of colonialism against Indigenous peoples. He suggests that this affects the suicide crisis because it discourages youth from being able to go to their ancestors for healing in times of trouble (Gallagher \& Williams, 2016). 
Saddened by the effects of Shoal Lake 40's land being expropriated, Sarain Carson-Fox discusses further on the importance in First Nation culture to graves and that they give a spiritual connection to the ancestors (Gallagher \& Williams, 2016). Sarain states,

They just dug up the graves and moved them. And so, we're just talking about like a huge machine, just digging in and ripping up bones and portions of people's bodies, and then just replacing them. And so, for me, that's what Shoal Lake is. So not only did they do that to the people who are living and breathing right now, but they did that to the ancestors. There was never any regard or respect for the people. The land that is most sacred to us, is also just a utility to the rest of Canada. (Gallagher \& Williams, 2016, 16:07).

Sarain discusses this issue of spiritual disrespect towards Indigenous people with Daryl while talking about the crisis of suicide in Shoal Lake 40. In these quotes, Daryl had explained to Sarain what his community used to be and then showed her what it was now (Gallagher \& Williams, 2016). Daryl shows Sarain this to address how these changes have affected the current youth suicide crisis, as one's relationship to the sacred land and ancestors are now hard to access for youth today (Gallagher \& Williams, 2016).

Looking at Back to Pikangikum (Rajotte, 2004), land, spirituality and culture are also significantly explored throughout the documentary. In an interview with Elder, Madeline Keeper, she discusses her experience with the abolishment of the clan system and how it had negatively influenced the community ever since, including the loss of six grandchildren to suicide over the years (Rajotte, 2004). In the English translation of Elder Madeline words, Coleen Rajotte explains, 
When Madeline grew up there was a clan system. It was the foundation of the community. There were seven clans, each represented by a totem animal. Each had clear responsibilities. Leadership, food gathering, education, defense, spiritual teachings, housing, and dispute resolution. Seven layers of cooperation. (Rajotte, 2004, 17:24). Discussing the clan system and how it had been slowly put away, community member, Fred, states,

Each group had a role to play. And when you have that defined, everybody in that community is active. Everybody has their tasks. What their function is. They would all have to work together to make a community function as a balanced community. (Rajotte, 2004, 18:06).

In understanding the theme of land, spirituality and culture, the effects of the clan system being torn down caused a disruption in the community's Indigenous culture and way of life throughout history (Rajotte, 2004). Moreover, Rajotte discusses how after the clan system died, missionaries came into communities and had instructed many First Nations people to get rid of traditional as well as cultural artifacts - such as, the drum (2004). The drum, particularly used in Pow-Wows, is described by Rajotte as being "used to celebrate marriages and the changing of seasons. It brought the community together and connected them to their ancestors" (Rajotte, 2004, 19:52). Regarding the loss of the drum, Fred states, Every Native community, you know they see the drum as the...the heart of the community. The beat, the heartbeat of the drum. That's the heartbeat of the community. When I go home to Pikangikum, you know...you don’t feel that. You know, there's no more heartbeat in Pikangikum cause the drum is gone. (Rajotte, 2004, 20:08). 
Reflecting on both Fred and Elder Madeline Keeper's words, it is important to understand how they talk about the power of culture in Pikangikum First Nation, as the removal of culture has affected the overall health of the community, including the suicide crisis (Rajotte, 2004). This is particularly due to the little access to cultural means of healing today than there used to be in the past for youth to turn towards (Rajotte, 2004).

In the documentary, Coleen Rajotte discusses with Indigenous Psychiatrist, Dr. Rod McCormick, on the suicide crisis happening in Pikangikum (2004). Within the theme of land, spirituality and culture, Dr. Rod McCormick discusses his nation-wide study on First Nation youth suicide and the protective factors his research had found related to suicide (Rajotte, 2004). He states,

Things I thought were a little surprising were spirituality, because usually for youth, it's not a strong source of support and empowerment for mainstream youth. And you know, I wasn't sure developmentally for many Aboriginal youth that would be strong, but it was a fairly strong component, as was culture, which makes sense. So, sense of belonging - if people felt that they belonged somewhere, then they were less likely to be suicidal. (Rajotte, 2004, 49:51).

Considering Dr. Rod McCormick's study on First Nation suicide, it is significant to highlight his findings on how strong cultural connections are within the protective factors for many youth as related to suicide risk (Rajotte, 2004).

In "Confronting Suicide Among Canada's Indigenous Communities" (2016), the theme of connectedness to land, spirituality and culture are present two times during the news episode. Medical Anthropologist, Gerald McKinley, touches upon this subject when he discusses the story of a young First Nations girl he met through work in one of the northern Ontario reserves, who 
had survived experiences with suicide ("Confronting Suicide Among Canada's Indigenous Communities...", 2016). Gerald states,

One of the communities that I visit... this young girl who was brave enough to share with our partners her own experience with pain and isolation. Because there is a strong connection between people who are self-harming and the suicides. But by reaching out and finding strength within her own community, within her own values and traditions she was able to find the strength that she needed to start looking for a better future for herself and now wants to work with other youth to build themselves up. ("Confronting Suicide Among Canada's Indigenous Communities...", 2016, 13:27).

Reflecting on Gerald's story, the theme of connectedness to land, spiritualty and culture are seen when he describes the experiences of a First Nation's girl who had found her strength by focusing back on her Indigenous values and traditions in order to heal from suicide and selfharming behaviours ("Confronting Suicide Among Canada's Indigenous Communities...", 2016). It is also valuable to note that Gerald addresses in the news episode that listening to the youth and their stories, such as this young girl's experience, will be what helps solve the suicide crisis in the future (“Confronting Suicide Among Canada's Indigenous Communities...", 2016). Within the news episode, Mi'kmaq Lawyer and Professor of Ryerson University, Pamela Palmater, discusses the theme of connectedness to land, spirituality and culture as well (“Confronting Suicide Among Canada's Indigenous Communities...”, 2016). Pamela is addressing the idea of hope within overcoming the issue of suicide amongst First Nation communities in northern Ontario and how connecting back to Indigenous culture is powerful for the youth of today (“Confronting Suicide Among Canada's Indigenous Communities...”, 2016). In conversation with the interviewers, Pamela states, 
One of the best features of who we are as Indigenous peoples, whether we are Haudenosaunee, Cree or Mi'kmaq, whenever any one of us are under attack. Whether it's the government raiding our communities or one of us is in a crisis, you always see other First Nation's standing up and coming to our aid. And I think that's where there's hope. I think there is a lot of strength in our own power, in our own sovereignty...more of us need to listen to the youth but also for the youth to have access to what's going on and to see these really positive steps...culture and language and nation building and all of those things. (“Confronting Suicide Among Canada's Indigenous Communities...”, 2016, 17:52).

It is significant to see how both Gerald and Pamela discuss strength in Indigenous traditions and culture for First Nation youth, because it highlights the importance of being connected their home community in addressing the suicide crisis ("Confronting Suicide Among Canada's Indigenous Communities...”, 2016).

\section{Conclusion}

Understanding the themes brought out from each of the two documentaries and the news episode, it is eminent that there are many interesting ideas addressed within the topic of the suicide crisis amongst First Nation youth in northern Ontario. It is interesting due to the many different themes emerging from the topic of First Nation youth suicide as well as the consistency across each data source to relate similar ideas. The themes of lack of access to resources, in terms of education, water, housing, health care and mental health, IRS and intergenerational trauma, grief and loss, as well as connectedness to land, spirituality and culture, were four of the most talked about themes throughout the research data. Drawing from the findings, I believe that these themes will be able to bring about meaningful and important ideas in the following 
Discussion chapter. Furthermore, I am eager to explore the deeper implications of these themes and interpret the findings within the context of the Influences on the Suicide Crisis amongst First Nation Youth in northern Ontario. 


\section{CHAPTER 6. DISCUSSION}

In this chapter, I will be discussing the findings found within the common themes in the previous chapter. Based on the documentaries, Cut-Off (Gallagher \& Williams, 2016) and Back to Pikangikum (Rajotte, 2004) as well as the news episode, Confronting Suicide Among Canada's Indigenous Communities (2016), my discussion will draw interpretations of the research data based on my theoretical framework and literature review. Moreover, I will address the results in terms of my research question, reflect on ethics, discuss strengths and limitations, and lastly, how my research might inform practice for the future, regarding First Nation youth suicide in northern Ontario.

\section{Lack of Access to Resources}

Considering the results that discuss the theme of lack of access to resources, I noticed that Cut-Off (Gallagher \& Williams, 2016), Back to Pikangikum (Rajotte, 2004), and "Confronting Suicide Among Canada's Indigenous Communities" (2016) frequently discussed the issue of power imbalances between First Nations people and non-First Nations people in relation to suicide. Reflecting directly towards my theoretical frameworks under an Indigenous paradigm, concepts of decolonizing theory (Kovach, 2010; Smith, 1997) and appreciative inquiry theory (Kaminski, 2012) are also seen in the findings. For example, Smith (1997) states how a decolonizing theoretical approach analyzes power differences between groups in hopes to encourage resistance and through that resistance, create structural change. Looking at the results, this is brought up in Cut-Off (Gallagher \& Williams, 2016), Back to Pikangikum (Rajotte, 2004), and "Confronting Suicide Among Canada's Indigenous Communities" (2016) where each source discuss the issue of power imbalances involved with having less resources. For example, power imbalances are shown throughout the issue with financial control in Rajotte (2004) and in 
"Confronting Suicide Among Canada's Indigenous Communities" (2016) when the problem of First Nation's children having less power than a child living in Toronto is discussed in terms of access to services that promote well-being, such as clean drinking water. I also noticed that the concepts of strength and endurance, as in appreciative inquiry theory (Kaminski, 2012) are shown in the findings. For example, the strength of First Nations people living in conditions where there is a lack of access to resources is shown in Gallagher and Williams (2016) and "Confronting Suicide Among Canada's Indigenous Communities" (2016), as they both discuss community strength in persevering through the hardships. Furthermore, "Confronting Suicide Among Canada's Indigenous Communities" (2016) highlights the importance of large-scale structural changes and giving autonomy back to First Nation communities to be the most effective way to approach suicide prevention for a better future.

Examining the research findings in relation to my literature review, I have found knowledge that confirms but also expands on the results. For example, Talaga (2017) discusses how the lack of access to mental health resources is involved in cases of suicide amongst First Nation communities in northern Ontario, which confirms results that were found. Furthermore, Gignac and Winter (2017) confirms results as well when they highlight that there is underfunding in communities for many needs, such as education and infrastructures that are needed to address the suicide crisis. Lastly, Palmater (2011) confirms the issue of the lack in basic necessities, such as water, food and sufficient housing to be an issue in many First Nation communities dealing with suicide. The existing literature also expands on the data, as Palmater (2011), states how many youth that experience the lack of resources are labelled as "troubled", highlighting how colonialism and racism are directly involved. Furthermore, Menzies (2010) expand on this data as the authors talks about racism and discrimination having an impact on 
trauma and allowing oppression, such as with lack of resources, to continue. Lastly, Mkandawire-Valhmu (2018) also expands this idea, as they state how racism can be involved in social environments of distinct power imbalance. It can also be seen that the findings stress a particular factor of this theme, for example the importance of funding is highlighted into their discussions on lack of resources. In relevant literature, Jones (2011) does infer that insufficient programming is related to the reliance on funding. Thus, it can be seen that the literature not only confirms the findings but do expand on what was found.

Relating back to my research question, the findings and the interpretation of those findings work together in exploring the influences on the current suicide crisis amongst First Nation youth in northern Ontario. They work together under the consideration of the theme, lack of access to resources, due to the information that is confirmed both in the literature review as well as the results. By looking at how this theme is shown to be addressed in regard to my research topic across all data sets, I have drawn that a community's access to resources or lack thereof appears to be an influencing factor within the youth suicide crisis occurring in northern Ontario First Nation communities.

\section{Indian Residential Schools and Intergenerational Trauma}

In relation to my theoretical framework, there are several implications that are seen throughout the research findings. In Cut-Off (Gallagher \& Williams, 2016) and Back to Pikangikum (Rajotte, 2004), the findings discuss the issue of First Nations children forced to give up their cultural traditions and assimilate into Canadian society through IRS and how it influences the current suicidality of youth. Looking at the results from a decolonizing and appreciative inquiry theoretical lens, I can see the factors that Kovach (2010) and Kaminski (2012) addresses to be key concepts in these theories. For example, Kovach (2010) states that 
decolonizing theory reveals how Indigenous knowledges have been marginalized in Western society. Noticing the effects of IRS discussed in Cut-Off (Gallagher \& Williams, 2016) and Back to Pikangikum (Rajotte, 2004), I can understand it as a marginalization of the Indigenous ways of life being invalidated through the involuntary assimilation into the Western world and cultural genocide. Furthermore, I acknowledge the existence of power dynamics (Smith, 1997) are present through the theme of IRS in the findings. For example, the results address the issue of abuse in IRS from figures of authority (Gallagher \& Williams, 2016; Rajotte, 2004; “Confronting Suicide Among Canada's Indigenous Communities...”, 2016), reflecting the power held by those in roles that oversaw and staffed the IRS. Furthermore, while intergenerational trauma is the carrying of direct or indirect trauma over generations through one's ancestors (Bombay et al., 2009), a form of power dynamics can be seen. As First Nations people continue to be traumatized by the abuse that occurred during IRS, First Nation youth are now experiencing the intergenerational effects that influence suicidality ("Confronting Suicide Among Canada’s Indigenous Communities...”, 2016).

Despite these issues, the results have also shown the life-giving forces that exist within First Nation communities in order to create the desired changes for the future (Kaminski, 2012). For example, “Confronting Suicide Among Canada's Indigenous Communities” (2016) discusses youth collaborating to create change for suicide prevention. Reflecting on this issue, there is a display of collective problem-solving by utilizing their collective strength as First Nation youth desiring to see change occur in their lives and in the lives of their people.

In context of my literature review, there is data that confirms the results indicated through my research findings. Discussed in McQuaid et al. (2017) and Bombay et al. (2019), the authors stated that IRS negatively impacted descendants of those who had attended these schools. 
Furthermore, Bombay et al. (2019) drew on the idea that the youth of family members who had attended IRS were more likely to face experiences of suicidal ideations and attempts. Drawing from Elias et al. (2012), the authors also address the theme of IRS, specifically highlighting the experiences of sexual abuse similar to abuse discussed in the research results. In addition, Kirmayer et al. (2003) and MacNeil (2008) also discuss and confirm concepts regarding IRS, as they address how IRS relates to the trauma and suicidality of First Nation youth. With this understanding, the findings confirm these ideas but present the data through a different perspective. For example, the results have utilized the unique personal narratives of those who had attended IRS or had family members who did, whereas the relevant literature focused more on generalizing those experiences overall. -Therefore, it can be seen that the idea of IRS influencing the current suicide crisis amongst First Nation youth in northern Ontario is reflected in both the literature review and the findings of my MRP, but the findings present the data in a different perspective.

Relating back to the research question of the influences on the suicide crisis amongst First Nation youth in northern Ontario, the literature review as well as the results have shown that the experience of IRS has impacted this crisis. Due to the intergenerational trauma following the abuse and cultural assimilation in IRS for First Nations people (Gallagher \& Williams, 2016; Rajotte, 2004; “Confronting Suicide Among Canada’s Indigenous Communities...”, 2016), suicide has become a crisis for First Nation youth living in northern Ontario communities.

\section{Grief and Loss}

Drawing from the results, I have noticed that there appears to be a collective experience of grief and loss that is discussed in the data. Specifically, the results have shown that within the First Nation communities addressed in Cut-Off (Gallagher \& Williams, 2016), Back to 
Pikangikum (Rajotte, 2004) and "Confronting Suicide Among Canada's Indigenous

Communities" (2016), most people, if not all, have lost someone to suicide or knows someone who has. In relation to appreciative inquiry theory and decolonizing theory (Kaminski, 2012;

Kovach, 2010), it is interesting to reflect on Kaminski's concept of collective potentials (2012). For example, as various extents of grief and loss are seen across the data for many First Nations communities, there can be much strength and empowerment through collective experience as shown in "Confronting Suicide Among Canada's Indigenous Communities" (2016). Furthermore, as grief and loss due to suicide is a common theme across the findings, there is the potential for new problem-solving approaches to occur for the purpose of influencing change for future suicide prevention (Kaminski, 2012). This is because throughout the findings, the data had displayed the idea of utilizing one another's stories of grief and loss to build each other back up, such as in Gallagher and Williams (2016). Moreover, in addressing suicide prevention, listening to the collective voices of those who have experienced suicide and loss to suicide is what will drive preventative strategies, such as what Joceyn Iahtail does in "Confronting Suicide Among Canada's Indigenous Communities" (2016). While considering the collective experience of grief and loss amongst First Nation communities, the strength and empowerment addressed formerly could also be thought of as a form of reclaiming power in the struggle. Specifically, the idea of power dynamics and challenging the marginalization of Indigenous knowledges, discussed in decolonizing theory (Kovach, 2010; Smith, 1997), can be important to taking back collective power and making Indigenous knowledges valid, through the use of individual voices or stories on grief and loss due to suicide. 
Drawing from the literature review, the existing data presented does not discuss the specific theme of grief and loss.$^{5}$ In consideration to the findings in my MRP, it appears that the results have discussed this topic in a different way from the current knowledge regarding suicide amongst First Nation youth in northern Ontario. Despite the literature review not directly inferring that grief and loss is an influence to the suicide crisis, Lafontaine (1998) does discuss the narrative of the principal's losses to suicide (Lafontaine, 1998), similar to the stories shared in Cut-Off (Gallagher \& Williams, 2016), Back to Pikangikum (Rajotte, 2004) and "Confronting Suicide Among Canada's Indigenous Communities" (2016). Furthermore, the literature had discussed the concept of collective trauma and discussed how grief and loss through colonization has added to the collective experience of trauma amongst Indigenous people (Kirmayer et al., 2003). Thus, the findings have shown similar ideas to what was presented in the relevant literature but has addressed it in a different way.

In awareness to my research question, I have noticed that the findings and the discussion have shown that grief and loss is an important influence to recognize within the First Nation youth suicide crisis in northern Ontario. Particularly, this is due to the stories shared in the findings that have addressed a person's losses in relation to suicidal ideations and/or attempts (Gallagher \& Williams, 2016; Rajotte, 2004; “Confronting Suicide Among Canada’s Indigenous Communities...”, 2016). Furthermore, it was found that the grief and loss of a friend, family or community member specifically to suicide, had influenced an individual's own experience with suicide as well as the community's overall suicide crisis (Gallagher \& Williams, 2016; Rajotte, 2004; “Confronting Suicide Among Canada’s Indigenous Communities...”, 2016). Therefore,

\footnotetext{
${ }^{5}$ Some relevant literature has shown the concept of cluster suicide (Eggertson, 2015; Dunn, 2013). As mentioned previously, the continuous series of deaths or cluster suicides occurring within months of each other can be shown to be influenced by a cycle of grief and loss. Though this is shown in the literature, I do not bring it into discussion in this chapter as it was not raised in the findings.
} 
the theme of grief and loss is an influence for youth suicide across First Nation communities in northern Ontario as well as an important factor that can drive future transformation for possible suicide prevention.

\section{Connectedness to Land, Spirituality and Culture}

Looking at the results from the theme of connectedness to land, spirituality and culture, I have understood the data strongly within the theoretical framework of decolonizing theory. Drawing Gallagher and Williams (2016), Rajotte (2004), “Confronting Suicide Among Canada's Indigenous Communities”, (2016), the issue of Indigenous land, spirituality and culture being taken away is discussed. Considering the key concepts of decolonizing and appreciative inquiry theory (Kovach, 2010; Kaminski, 2012), I recognize the marginalization of Indigenous knowledges in Western context as discussed in Kovach (2010). By replacing the Indigenous ways of life with Western knowledges as well as dispossession of land as discussed in the findings, I understand how Indigenous land, spirituality, and culture amongst First Nations people have been silenced and disrespected. Furthermore, in considering the key concept of power dynamics within decolonizing theory (Smith, 1997), I understand the disrespect of Indigenous traditional ways and taking over of land as an exercise of power from those that were White. Through the marginalization and power imbalance regarding First Nation land, spirituality and culture, the results show its influence on the youth suicide crisis today as youth have lost their sense of identity and healing through this issue. Addressed in "Confronting Suicide Among Canada's Indigenous Communities" (2016), the experience of youth finding strength in their community through culture was discussed. Despite one's history with suicidal ideations, the findings discuss the collective support of community in hopes to achieve a more desired future of healing, as highlighted in Kaminski (2012)'s appreciative inquiry theory. 
Furthermore, the findings have shown First Nation communities have come together to stand up for the youth suicide crisis, while focusing on the purpose nation building, culture and language, also highlighted in appreciative inquiry theory. In considering these findings within the context of connectedness to land, spirituality and culture, the role of collective power to problem-solve and make future change (Kaminski, 2012). is emphasized.

Drawing from the literature review, the results of my research appear to confirm what was found in relevant literature. Reflecting on connectedness to land, spirituality and culture, the importance of culture and one's relationship with Indigenous traditions is highlighted in the literature, which is similar to the ideas brought out through the data results (Gallagher \& Williams, 2016; Rajotte, 2004; “Confronting Suicide Among Canada’s Indigenous Communities...", 2016). For example, relevant literature from Bodnar (2014), Chandler and Lalonde (2009), Hallett et al. (2007), Kirmayer et al. (2000), Kirmayer et al. (2003), MacNeil (2008), and McCormick et al. (2013) discuss the concept of cultural continuity and how it influences suicidality amongst Aboriginal youth. In understanding the data results, the research had also highlighted the importance of cultural continuity in both influencing suicidality but also as a way of prevention. Though the findings confirm what was seen in the literature review, it was shown in a different way. The findings did not explicitly talk about the concept of cultural continuity in a community but rather the importance of one's relationship to culture for healing influencing suicidality as well as a preventative factor. Therefore, drawing on the idea of connectedness to land, spirituality and culture in the findings, the data results have not only confirmed what the relevant literature has shown but addressing the same concepts in a different way. . 
Furthermore, in relation to the youth suicide crisis, Ma et al. (2019) discuss the issue about over-involvement in child welfare for Indigenous children and the need for more culturally appropriate services to exist. By looking at the importance of child welfare in valuing the unique culture within Indigenous families (Ma et al., 2019), my findings do not address child welfare specifically but the importance of culture and its major influence on the suicide crisis amongst First Nation youth in northern Ontario (Gallagher \& Williams, 2016; Rajotte, 2004; “Confronting Suicide Among Canada's Indigenous Communities...”, 2016). Factors such as a lack of individual and community cultural continuity as well as not having a connection to culture for healing were seen as influences for suicidality amongst First Nation youth, as noted in the literature; these factors, in combination with discrimination and the lack of consideration about connection to culture for child welfare services were also described as influencing suicidality amongst First Nation youth (Blackstock, 2010; Ma et al., 2019; McKenzie, 1997). Therefore, the results shown in the data analysis do differ in this way from the information in the literature review. They differ in how the topic child welfare does not show up as a theme or discussion within the findings, but in the literature review by Ma et al. (2019).I believe the findings do not discuss child welfare directly potentially due to the inferences already made within the theme of IRS, such as in "Confronting Suicide Among Canada's Indigenous Communities" (2016) where it mentioned the idea of Indigenous children being take away throughout history.

Considering my research question, the results have shown the importance and influence of one's connectedness to land, spirituality and culture in the First Nation youth suicide crisis in northern Ontario. Reflecting on the existing literature, such as the concept of cultural continuity as a risk and preventive factor to suicide, my findings have confirmed and built on the 
knowledge in relation to the discussed theme. Therefore, the current existing knowledge and results seen in Gallagher and Williams, (2016), Rajotte (2004) and "Confronting Suicide Among Canada's Indigenous Communities" (2016) have shown that connectedness to land, spirituality and culture is a strong influence on the suicide crisis amongst First Nation youth in northern Ontario.

\section{Understanding the Research Question}

Reflecting on each of the themes that were found through the data results, I notice how they all work together in answering my research question. In particular, each of these factors had shown to be implicated within the context of suicide. Furthermore, I have gathered that each of these topic discussions are more than just themes, but real experiences of people that speak to the seriousness of youth suicide in First Nation communities. With this understanding, the results show that the social conditions of receiving little to no resources in a community, the experience of intergenerational trauma from ancestors attending IRS the experience of losing someone you know to suicide and the grief afterwards, and a person's connection with the land, their spirituality and culture are all influences on the suicide crisis amongst First Nation youth in northern Ontario (Gallagher \& Williams, 2016; Rajotte, 2004; “Confronting Suicide Among Canada’s Indigenous Communities...”, 2016).

\section{Ethics}

In regard to ethics, this research did not require REB approval, due to the methodology of my research being SDA of publicly available sources and not utilizing the resources of human participants. Throughout my research I was not faced with any major ethical issues, even though I did consider what these may be prior to the data collecting process. For example, I had acknowledged potential risks of revealing personal identities of individuals, but that risk was 
mitigated by not researching further into one's identity other than what was already consented for in the two documentaries and news episode. I had also considered how this research would implicate myself, as a researcher. Even though I had formerly addressed my personal implications in my MRP, I do understand the privilege I carry by not having to live this experience everyday compared to the reality of many First Nations people who live in these suicide crises. Understanding the concerns of non-Indigenous researchers researching on Indigenous people, I have chosen to still move forward, as my MRP highlights Indigenous voices and experiences of those directly impacted by the youth suicide crisis. Furthermore, I do acknowledge my personal and professional experience with the suicide crisis in northern Ontario reserves that had brought me to discuss this issue.

\section{Strengths and Limitations}

As it is important in qualitative research, I will be discussing what the strengths and limitations may be in consideration to my research topic.

Recognizing the strengths, Whittemore et al. (2001) address several areas that make SDA research valid. For a few examples, Whittemore et al. (2001) states that vividness, referring to "the presentation of thick and faithful descriptions with artfulness, imagination, and clarity" (p. 531) portrays the essence of phenomena without details that are too excessive. In addition, explicitness, which refers to the "explicit presentation of results" (p. 531) provides support and evidence for conclusions and inferences made by researchers. Considering both vividness and explicitness in my MRP, I believe that these are major strengths seen through the data collection and analysis process. Due to the use of SDA, I was able to gather pre-existing information that used the first-hand stories and voices of those that were First Nation in the findings, which shows explicitness. Furthermore, the interpretation was done on a basis of what the findings showed 
and not necessarily what I was seeking to find. For example, there were themes that presented in the findings that had been described in a different perspective to the relevant literature, such as grief and loss. Specifically, the results did not talk about cluster suicides directly, like in Eggertson (2015) and Dunn (2013), but the narratives in the data I examined addressed the impact of losing someone to suicide on the suicidality of others in that community. Moreover, using quotes directly in the context of the portrayed themes from the data as well as choosing details that explicitly discussed First Nation youth suicide in northern Ontario, I believe show vividness in my research. Another strength can be drawn from sensitivity, as Whittemore et al. (2001) address. Sensitivity, which "refers to research that is implemented in ways that are sensitive to the nature of human, cultural, and social contexts" (Whittemore et al., 2001, p. 532) is important in my research as the focus population is First Nation youth. As a researcher, I need to be aware of the rich cultural background as well as history of Indigenous peoples. For example, it is important to be aware of the colonial oppression of Indigenous peoples throughout history that still occurs today and the social conditions that continue to marginalize their community, which I made sure to understand prior to researching. Furthermore, I choose to utilize sources that allowed First Nation individuals to speak for themselves and speak about what they feel the issues are for their communities regarding the suicide crisis. Lastly, I had chosen SDA as a way to mitigate risk of retraumatizing human participants in discussing the sensitive topic of suicide. Another strength in the research is in regard to thoroughness. In Whittemore et al. (2001), the authors describe thoroughness as the findings convincingly addressing the questions made with saturation and completeness. Through the data findings and analysis, I believe the research question had been answered as completely as it could in this context, as many themes regarding the influences to suicide amongst First Nation youth were 
drawn across the data sources. Moreover, the findings had confirmed and shown, although through a different perspective, similar ideas to what was found in relevant literature.

There are some limitations that exist. In Whittemore et al. (2001) the authors discuss the concept of creativity, which refers to the research being flexible within the process of inquiry "and imaginative ways of organizing, presenting, and analyzing data" (p. 532). Understanding creativity, I believe my research could have been more creative in the way that it was presented. For example, my research could have utilized more visual data or graphs. Furthermore, due to the constraints of my research being shown through a written MRP, I was not able to explore other methods such as, oral presentations or through an art project. Another way my research is limited is in context of congruence. Whittemore et al. (2001) explain congruence as the research being about to fit into contexts outside research situation as well as connectedness between theory and methodology, findings and research question, data collection and analysis, and current studies with previous studies. Reflecting on my MRP, the research is congruent in that the methodology and theories work coherently, for example Indigenous paradigm and decolonizing theory. Furthermore, the relevant literature and findings are connected as they reflect similar themes. But I believe congruence is limited in the way that these findings may not fit into contexts outside of this particular situation regarding suicide. For example, the findings should fit into the context of First Nation youth living in northern Ontario communities, but the findings may not be similar for First Nation youth living in southern Ontario communities, as their experience of suicide could be drastically different.

In addition, there are limitations that exists in regard to myself being a non-Indigenous researcher as well as much of the knowledge found already discussed in relevant literature. As a non-Indigenous research, there had been limitations in researching on a topic about Indigenous 
people and issues. For example, I had encountered issues when considering methodology. In reflecting on an Indigenous paradigm, I was worried about how I would be able to utilize this paradigm without cultural appropriation or speaking on a topic as if I know more than a researcher who is Indigenous. In overcoming this issue, I had decided on an Indigenousinformed paradigm through the work of Kovach (2010). I had chosen to go forward with this due to taking my relationships in my professional and personal life with First Nation communities in northern Ontario into consideration. In reflecting on the concepts drawn in Pidgeon (2019) and Puch-Bouwman (2014) about the concerns on non-Indigenous researchers doing Indigenous research and thus, how to conduct it in the most appropriate way, I was able to ethically continue my research to the best of my ability. For example, I focused on First Nation voices being centered in discussing what they believe their issues are as well as reflecting several times on my position as a non-Indigenous person in relation to the research.

Furthermore, another limitation to the research is that the findings did not appear to uncover new knowledge, but rather confirming the literature through different perspectives. Reflecting on the themes, the findings had drawn upon what was seen in the relevant literature but utilized the primary narratives of those who were First Nation living in northern Ontario communities to express similar ideas in a different way. For example, in the findings, the results had discussed the idea of cluster suicides but never addressing cluster suicide directly. Rather, the findings talked about this phenomenon through the concept of grief and loss of community members by suicide to influence the suicidality of others in the community over a period of time. Moreover, in discussing the influence of cultural continuity on suicidality of First Nation youth, the findings confirmed what was said in existing literature but addressed this concept through the idea of one's relationship with culture and identity impacting suicide and suicide prevention. 
In acknowledging the research process, there were many critiques brought up from the second reader who reviewed my MRP. The second reader had addressed that there is much literature that already exists on the topic and concepts I had originally missed in the literature. Through going back and doing a second review of literature, I was able to uncover several articles and studies that added to my research and showed there were not the gaps in existing knowledge that I had first thought. Furthermore, researching through the literature again had helped me to find data that confirmed what was being brought out in the findings and ultimately, changed my interpretations of what the findings show me. For example, I had felt that the findings discovered new knowledge, but that was not what had happened. Instead, there was much relevant literature that did express what I thought was new knowledge, but the issue was with the keyword combinations I was using. After considering the second reader's critique and looking through literature another time, I found existing literature that related to the concepts in the findings and helped enhance my MRP overall.

The second reader had also made critiques regarding how I had believed that Indigenous knowledges or paradigms with other theories would be better than simply just using an Indigenous paradigm. Specifically, the second reader stated that they fundamentally disagreed with this idea and argued that Indigenous knowledge base can be used on its own. After reflecting on the critique, I realized that it was not that an Indigenous paradigm is limited in any way for my research, but rather myself being a non-Indigenous researcher utilizing Indigenous paradigms would serve as a limitation. Therefore, I had addressed this concern throughout my MRP and recognized that my position as a non-Indigenous person was the limitation.

In the future, I believe that there are areas I can continue to address beyond this MRP. As also brought up from the second reader, the topic on First Nation youth suicide has been over- 
researched. Therefore, it is wise that in future research efforts that the focus be targeted not on why suicide amongst First Nation youth is happening, but ways in which suicide prevention can be better addressed and carried forth into communities across northern Ontario, such as, addressing the social and political oppressions of First Nations people, which I address in Chapter 7.

\section{Conclusion}

In this chapter, I have discussed the results in relation to the themes presented throughout the findings chapter. Through addressing the implications and the connections to the theoretical framework, the data has shown the influences of the lack of access to resources, IRS, grief and loss, and one's connectedness to land, spirituality and culture on the suicide crisis amongst First Nation youth in northern Ontario. Furthermore, I have considered the ethics of this research and explained why REB approval was not needed due to the use of SDA. Lastly, I addressed the strengths and limitations in the context of qualitative research on the Influences on the Suicide Crisis amongst First Nation Youth in northern Ontario. In the following chapter, I will be summarizing the overall key points as well as discussing implications for social work practice. 


\section{CHAPTER 7. CONCLUSION}

Reflecting on the presented data, there are ways that I believe it can be implicated for both future research in this area as well as social work practice. In considering that the methodology employed the use of SDA, it would be interesting to explore different research approaches in the future. For example, it might have been helpful to conduct primary research that involved the use of human participants, with respect and sensitivity to the First Nation youth suicide crisis. I believe human participants could provide a richer and more valuable experience as a researcher, through face-to-face interaction with people. Furthermore, I am curious to know how the results in the findings could change over time and whether there are better preventative measures in place that respond to this current issue. The First Nation youth suicide crisis is a topic that is starting to be seen as over-researched. In Ansloos (2018), the author explains how there has been substantial research regarding Indigenous suicide amongst adults and youth, but that "little remains known about effective means to reduce Indigenous deaths by suicide" (p. 9). Understanding the need for solutions, there have been efforts for suicide prevention over the years but mainly from a psychological and individualistic point of view (Ansloos, 2018). Therefore, Ansloos (2018) suggests the need for more of a prevention grounded approach from a cultural lens that focuses on the social and political concerns of communities. With this understanding, there is more than enough research that exists on the topic of suicide among First Nations youth. What is important now is to take the existing knowledge into future suicide prevention and plans of action within the broader context of the structural, political and social conditions that are influencing suicide rather than viewing suicide as a psychological experience that needs to be treated individually. Furthermore, I believe suicide prevention is not a matter of continuous research but to act on the issues seen throughout the findings that are contributing to 
the crisis of suicide amongst First Nation youth - such as addressing the lack of clean water and resources in many First Nation communities (Gallagher \& Williams, 2016) or through the reclaiming of cultural continuity address in the relevant literature and findings.

Understanding that the results found several themes that had related to my research question, I believe that future studies on the Influences on the Suicide Crisis amongst First Nation Youth in northern Ontario could expand on these ideas or even provide new themes not brought up in this study. In hopes that I may be presented with the opportunity to research this issue once more, I would like to consider different avenues of data analysis related to this topic, such as case studies, thematic analysis, or narrative inquiry. These particular approaches may be helpful as it could allow me to create new meanings and knowledge due to the use of primary information from human participants.

By implicating future social work practice, I believe that this research can encourage deeper and stronger relationships with First Nations people and communities. Furthermore, I would like to see social work practice providing more culturally-appropriate services that recognize the unique history and oppression of Indigenous people - especially in the context of youth suicide. As a social worker, I recognize the ways in which the profession has been complicitan active participant in colonization. For example, social work has a long record of involvement in the residential school system and forcibly removing children from homes into foster care during the Sixties Scoop, leading to trauma and cultural disconnection for First Nations people (Burke, 2018). Through acknowledging what harm has been done and making efforts to move forward, I believe this can open space for new dialogue to occur with Indigenous people in Canada. 
First Nation youth suicide is addressed as a crisis throughout the research. As Indigenous people continue to be oppressed in the Canadian society, many First Nation youth are suffering with the thoughts of suicide or attempts at suicide (Gallagher \& Williams, 2016; Rajotte, 2004; “Confronting Suicide Among Canada’s Indigenous Communities...”, 2016). Discussed throughout the research, there are many influences currently involved with this issue. Understanding the results shown in Cut-Off (Gallagher \& Williams, 2016), Back to Pikangikum (Rajotte, 2004) and “Confronting Suicide Among Canada's Indigenous Communities” (2016), First Nation communities across northern Ontario are faced with constant struggles that continue to further marginalize them. Understanding how a community's lack of access to resources, history of IRS involvement, experience with grief and loss to suicide, and connectedness to land, spirituality and culture were themes in the data, it appeared that a First Nation community's lack of access to resources was the most discussed influence on their youth suicide crisis (Gallagher \& Williams, 2016; Rajotte, 2004; “Confronting Suicide Among Canada's Indigenous Communities...”, 2016)

. The research also displayed several other findings, such as the impact of IRS and intergenerational trauma impacting First Nation youth suicide (Gallagher \& Williams, 2016; Rajotte, 2004; “Confronting Suicide Among Canada’s Indigenous Communities...”, 2016). Furthermore, the grief and loss from losing someone a person knows to suicide and one's connectedness to land, spirituality and culture were seen as influencing the suicidality amongst First Nation youth (Gallagher \& Williams, 2016; Rajotte, 2004; “Confronting Suicide Among Canada’s Indigenous Communities...”, 2016).

In writing this MRP, the feedback received from the second reader not only influenced the way in which I revised this MRP but has also influenced how I will continue to practice 
social work with Indigenous communities moving forward. As a non-Indigenous social worker, the second reader feedback challenged what I thought I knew as well as taught me new ways of thinking in the process. Before writing this MRP, I had originally felt like I understood how to reflect on myself as a non-Indigenous person working with Indigenous people, such as considering the effects of colonialism that continue to marginalize those that I worked with. Furthermore, I had believed that I was doing the self-reflexive process in order to constantly check my own privilege. In considering the second reader feedback, I had not done these things as well as I thought. Rather, I was merely touching the surface level and needed to go deeper. Reflecting on this process, I have learnt that I need to challenge myself to go further in recognizing my positionality and privilege in my practice moving forward. For example, not just viewing privilege as black and white, but to recognize the complex layers that comes with such privilege every day. Furthermore, I had also come to a realization from the second reader feedback that I have a hard time with critique, as I had previously felt I did what I needed to do in order to make this MRP the best it could. I now understand that critique is a constant process and that it is okay to be challenged, as that is the only way I can grow. Understanding how I am implicated in this field of work, I need to be open to criticism and allow myself to be stretched in new ways. Such ways may include opening up more time with community members when the methods of support and interventions I am using are not working anymore. By doing this, I not only acknowledge the needs of the community and highlight their voices, but I am also better able to support them through developing my social work practice within our changing society.

Considering the results that were drawn from the data, I had discussed a few implications to both research and social work practice. By reflecting on the research done in this MRP, the hopes are that the findings can encourage further research to occur in order to develop new 
suicide prevention strategies in the future. Some communities have already started suicide prevention strategies, for example the community of Wapekeka First Nation after the loss of two young girls to suicide within days of one another (Galloway, 2017). Due to funding from an anonymous donor, Wapekeka has been able to implement on-reserve mental health services, utilizing workers living in the community to address the community's grief and loss to suicide (Galloway, 2017). Moving forward, I believe that this research can also help social work practice in the way social workers interact with Indigenous people in Canada and the services provided to communities in northern Ontario. Through proper attention to Indigenous culture, decolonization of self and practice, and building relationships with First Nation communities, I believe the suicide crisis can be better addressed moving forward. Lastly, the voices of those directly impacted by this crisis need to continue being heard. Inspired by the words of Pamela Palmater, the youth need to be listened to ("Confronting Suicide Among Canada's Indigenous Communities...", 2016). In knowing what the youth want and what the youth need, that is the most comprehensive way to respond to the First Nation youth suicide crisis in northern Ontario. 


\section{REFERENCES}

Ansloos, J. (2018). Rethinking Indigenous suicide. International Journal of Indigenous Health, 13(2), 8-28. doi:10.18357/ijih.v13i2.32061

Barker, J., \& Alldred, P. (2012). Documentary research and secondary data. In S. Bradford \& F. Cullen (Eds.), Research and research methods for youth practitioners, (pp. 40-161). Routledge. doi:10.4324/9780203802571

Baskin, C. (2016). Strong helpers' teachings: The value of indigenous knowledges in the helping professions (2nd ed.) Canadian Scholars' Press.

Blackstock, C. (2010). When everything matters: Comparing the experiences of First Nations and non-Aboriginal children removed from their families in Nova Scotia from 2003 to 2005. [University of Toronto]. ProQuest Dissertations Publishing

Bodnar, A. (2014). Perspective on Aboriginal suicide: Movement toward Healing. In P. Menzies, L. Lavallée \& E. V. Harper (Eds), Journey to healing: Aboriginal people with addiction and mental health issues, what health, social service and justice workers need to know, (pp. 285-299), Centre for Addiction and Mental Health (CAMH).

Bombay, A., Matheson, K.\& Anisman, H. (2009). Intergenerational trauma: Convergence of multiple processes among First Nations peoples in Canada. Journal of Aboriginal Health, 5(3), 6-47.

Bombay, A., McQuaid, R. J., Schwartz, F., Thomas, A., Anisman, H., \& Matheson, K. (2019). Suicidal thoughts and attempts in First Nations communities: Links to parental Indian residential school attendance across development. Journal of Developmental Origins of Health and Disease, 10(1), 123-131. doi:10.1017/S2040174418000405 
Brady, B., Veljanova, I., \& Chipchase, L. (2016). Culturally informed practice and physiotherapy. Journal of Physiotherapy, 62(3), 121-123. doi:10.1016/j.jphys.2016.05.010

Burke, S. (2019). Teaching the history of colonization in the postsecondary classroom. Journal of Social Work Education, 55(4), 658-668. doi:10.1080/10437797.2019.1611510

Button, M. E. (2016). Suicide and social justice: Toward a political approach to suicide. Political Research Quarterly, 69(2), 270-280. doi:10.1177/1065912916636689

Chandler, M., \& Lalonde, C. (1998). Cultural continuity as a hedge against suicide in Canada's First Nations. Transcultural Psychiatry, 35(2), 191-219.

Chandler, M. J., \& Lalonde, C. E. (2008). Cultural continuity as a protective factor against suicide in First Nations youth. Horizons, 10(1), 68-72.

Clark, G. (2005). Secondary data. In R. Flowerdew \& D. M. Martin (Eds.), Methods in human geography: A guide for students doing a research project (2nd ed, pp. 57-73). Taylor \& Francis.

Confronting suicide among Canada's Indigenous communities. (2016, April 18). Al Jazeera. https://www.aljazeera.com/programmes/thestream/2016/04/25192200324115030414.html

Cutcliffe, J. R. (2005). Toward an understanding of suicide in First-Nation Canadians. Crisis: The Journal of Crisis Intervention and Suicide Prevention, 26(3), 141-145. doi:10.1027/0227-5910.26.3.141

Deal, K. H. (2007). Psychodynamic theory. Advances in Social Work, 8(1), 184-195. doi: $10.18060 / 140$ 
Dunn, E. R. (2013). The influence of belief in a positive afterlife on youth suicide in a northwestern Ontario First Nation [Walden University]. ProQuest Dissertations Publishing.

Eggertson, L. (2013). Inuit leaders announce national Inuit suicide-prevention strategy. Canadian Medical Association Journal (CMAJ), 185(15), E703-E704. doi:10.1503/cmaj.109-4601

Eggertson, L. (2015). Aboriginal youth suicide rises in northern Ontario. Canadian Medical Association Journal, 187(11), 335-336. doi:10.1503/cmaj.109-5108

Elias, B., Mignone, J., Hall, M., Hong, S. P., Hart, L., \& Sareen, J. (2012). Trauma and suicide behaviour histories among a Canadian Indigenous population: An empirical exploration of the potential role of Canada's residential school system. Social Science \& Medicine, 74(10), 1560-1569. doi:10.1016/j.socscimed.2012.01.026

Farley, M., Lynne, J., \& Cotton, A. J. (2005). Prostitution in Vancouver: Violence and the colonization of First Nations women. Transcultural Psychiatry, 42(2), 242-271. doi: $10.1177 / 1363461505052667$

Fontaine, P., \& Truth and Reconciliation Commission of Canada. (2016). A knock on the door: The essential history of residential schools from the Truth and Reconciliation Commission of Canada. University of Manitoba Press. doi:10.5860/choice.197013

Gallagher, M., \& Williams, J. L. (Director). (2016). Cut-Off [Film]. Vice Studio Canada. Galloway, G. (2017, Jan 25). Private donor funds suicide-prevention program for Ontario First Nation community. The Globe and Mail. Retrieved from http://ezproxy.lib.ryerson.ca/login?url=https://www-proquestcom.ezproxy.lib.ryerson.ca/docview/2383283490?accountid=13631 
Gignac, J., \& Winter, J. (2017, Jul 07). First Nations are shaken by four suicides in one week: N. Ontario communities struggle to cope with deaths of three youths, one man. Toronto Star. Retrieved from http://ezproxy.lib.ryerson.ca/login?url=https://search-proquestcom.ezproxy.lib.ryerson.ca/docview/1916647975 accountid=13631

Graham, J., \& Bruhn, J. (2009). Improving health governance in First Nations communities: Model governance policies and tools. Institute on Governance.

Greeno, E. J., Fedina, L., Rushovich, B., Moore, J. E., Linsenmeyer, D., \& Wirt, C. (2017). "They tippy toe around the race issue": The impact of a title IV-E program on culturally informed practice for child welfare students. Child \& Family Social Work, 22(4), 13741382. doi:10.1111/cfs. 12355

Hallett, D., Chandler, M. J., \& Lalonde, C. E. (2007). Aboriginal language knowledge and youth suicide. Cognitive Development, 22(3), 392-399. doi:10.1016/j.cogdev.2007.02.001

Hamdullahpur, K., Jacobs, K. J., \& Gill, K. J. (2018). Mental health among help-seeking urban women: The relationships between adverse childhood experiences, sexual abuse, and suicidality. Violence Against Women, 24(16), 1967-1981.

doi:10.1177/1077801218761602

Jones, A. (2011, Sep 03). Feds urged to build school on Ontario First Nation to help prevent youth suicides: Community believed to have highest suicide rate in world. Prince Albert Daily Herald. Retrieved from http://ezproxy.lib.ryerson.ca/login?url=https://searchproquest-com.ezproxy.lib.ryerson.ca/docview/2003321050?accountid=13631

Kaminski, J. (2012). Appreciative inquiry theory. Canadian Journal of Nursing Informatics, $7(1)$. 
Kilian, A., Fellows, T. K., Giroux, R., Pennington, J., Kuper, A., Whitehead, C. R., \& Richardson, L. (2019). Exploring the approaches of non-Indigenous researchers to Indigenous research: A qualitative study. CMAJ Open, 7(3), E504-E509. doi:10.9778/cmajo.20180204

Kirmayer, L. J., Brass, G. M., \& Tait, C. L. (2000). The mental health of Aboriginal peoples: Transformations of identity and community. The Canadian Journal of Psychiatry, 45(7), 607-616. doi:10.1177/070674370004500702

Kirmayer, L., Simpson, C., \& Cargo, M. (2003). Healing traditions: Culture, community and mental health promotion with Canadian Aboriginal peoples. Australasian Psychiatry, 11(1), S15-S23. doi:10.1046/j.1038-5282.2003.02010.x

Kovach, M. (2010). Indigenous methodologies: Characteristics, conversations, and contexts. University of Toronto Press.

Lafontaine, C. (1998). Using the experience of a First Nation principal with student suicide in a First Nation school for structuring policy problems (Order No. MQ30498). Available from ProQuest Dissertations \& Theses A\&I; ProQuest Dissertations \& Theses Global. (304440602).

Ma, J., Fallon, B., \& Richard, K. (2019). The overrepresentation of First Nations children and families involved with child welfare: Findings from the Ontario incidence study of reported child abuse and neglect 2013. Child Abuse \& Neglect, 90(1), 52-65. doi:10.1016/j.chiabu.2019.01.022

MacNeil, M. S. (2008). An epidemiologic study of Aboriginal adolescent risk in Canada: The meaning of suicide. Journal of Child and Adolescent Psychiatric Nursing, 21(1), 3-12. doi:10.1111/j.1744-6171.2008.00117.x 
Maranzan, K. A., Sabourin, A., \& Simard, C. (2011). First Nations women in northern Ontario: Health, social, and community priorities. International Indigenous Policy Journal, 2(1). doi:10.18584/iipj.2011.2.1.9

McCormick, R., Thira, S., Arvay, M., \& Rinaldis, S. (2013). In their own words: A retrospective exploratory study of how to facilitate healing for suicidal Indigenous youth. In J. R. Cutcliffe, J. Santos, P. S. Links, J. Zaheer, H. G. Harder, F. Campbell, R. McCormick, K. Harder, Y. Bergmans \& R. Eynan (Eds), Routledge international handbook of clinical suicide research (pp. 351-363). Routledge. doi:10.4324/9780203795583

McKenzie, B. (1997). Developing First Nations child welfare standards: Using evaluation research within a participatory framework. The Canadian Journal of Program Evaluation, 12(1), 133-148.

McQuaid, R. J., Bombay, A., McInnis, O. A., Humeny, C., Matheson, K., \& Anisman, H. (2017). Suicide ideation and attempts among First Nations peoples living on-reserve in Canada: The intergenerational and cumulative effects of Indian residential schools. The Canadian Journal of Psychiatry, 62(6), 422-430. doi:10.1177/0706743717702075

Merriam, S. B., \& Grenier, R. S. (2019). Qualitative research in practice: Examples for discussion and analysis (2nd ed.). Jossey-Bass.

Mew, E. J., Ritchie, S. D., VanderBurgh, D., Beardy, J. L., Gordon, J., Fortune, M., Orkin, A. M. (2017). An environmental scan of emergency response systems and services in remote First Nations communities in northern Ontario. International Journal of Circumpolar Health, 76(1). doi:10.1080/22423982.2017.1320208

Mkandawire-Valhmu, L. (2018). Cultural safety, healthcare and vulnerable populations: A critical theoretical perspective. Routledge. doi:10.4324/9781315708706 
Nash, K., \& Corner, J. (2016). Strategic impact documentary: Contexts of production and social intervention. European Journal of communication, 31(3), 227-242. doi:10.1177/0267323116635831

Nault, R. D. (2017, Jul 24). First Nations suicide epidemic in northern Ontario requires immediate action. The Toronto Star. Retrieved from http://ezproxy.lib.ryerson.ca/login?url=https://www-proquestcom.ezproxy.lib.ryerson.ca/docview/1922853010?accountid=13631

Olsen, T. A. (2018). Privilege, decentring and the challenge of being (Non-) Indigenous in the study of indigenous issues. The Australian Journal of Indigenous Education, 47(2), 206215.

Palmater, P. D. (2011). Stretched beyond human limits: Death by poverty in First Nations. Canadian Review of Social Policy, 1(65), 112-127.

Pidgeon, M. (2019). Moving between theory and practice within an Indigenous research paradigm. Qualitative Research, 19(4), 418-436. doi:10.1177/1468794118781380

Puch-Bouwman, J. (2014). A promised mindland?: A rectificatory theory-practice position for non-Indigenous researchers. AlterNative: An International Journal of Indigenous Peoples, 10(4), 408-421. doi: 10.1177/117718011401000407

Rajotte, C. (Director). (2004). Back to Pikangikum [Film]. Winnipeg Film Group.

Roberto, K. A., McCann, B. R., \& Brossoie, N. (2013). Intimate partner violence in late life: An analysis of national news reports. Journal of Elder Abuse \& Neglect, 25(3), 230-241. doi:10.1080/08946566.2012.751825

Sales, E., Lichtenwalter, S., \& Fevola, A. (2006). Secondary analysis in social work research 
education: Past, present, and future promise. Journal of Social Work Education, 42(3), 543-560. doi:10.5175/JSWE.2006.200404136

Smith, G. (1997). The development of Kaupapa Maori: Theory and praxis. University of Auckland.

Tempier, R. (2016). Suicide among Aboriginals: A “burning” public health issue in need of solutions. Canadian Journal of Psychiatry, 61(11), 682-683.

doi:10.1177/0706743716655787

Trocmé, N., Fallon, B., MacLaurin, B., Sinha, V., Black, T., Fast, E., Felstiner, C., Hélie, S., Turcotte, D., Weightman, P., Douglas, J., \& Holroyd, J. (2010). Canadian Incidence Study of Reported Child Abuse and Neglect 2008: Major findings. Public Health Agency of Canada. doi:978-1-100-16915-6

Vowel, C. (2016). Indigenous writes: A guide to First Nations, Métis and Inuit issues in Canada. High Water Press.

Waldram, J. B. (2004). Revenge of the windigo: The construction of the mind and mental health of North American Aboriginal peoples. University of Toronto Press.

Whittemore, R., Chase, S. K., \& Mandle, C. L. (2001). Validity in qualitative research. Qualitative Health Research, 11(4), 522-537. doi:10.1177/104973201129119299 